\title{
Supported Tantalum Oxide and Supported Vanadia-tantala Mixed Oxides: Structural Characterization and Surface Properties
}

\author{
Michael Baltes,,$\nmid$ Arla Kytökivi, ${ }^{\ddagger}$ Bert M. Weckhuysen, ${ }^{\S}$ Robert A. Schoonheydt," \\ Pascal Van Der Voort, ${ }^{\dagger}$ and Etienne F. Vansant ${ }^{\dagger}$ \\ Laboratory of Adsorption and Catalysis, Department of Chemistry, University of Antwerpen (U.I.A.), \\ Universiteitsplein 1, 2610 Wilrijk, Belgium, Fortum Oil and Gas Oy, Oil, Research and Development, \\ POB 110, 00048 Fortum, Keilaranta 6, Espoo, Finland, Department of Inorganic Chemistry and Catalysis, \\ Debye Institute, University of Utrecht, Sorbonnelaan 16, PO Box 80083, 2508 TB Utrecht, The Netherlands, \\ and Centrum voor Oppervlaktechemie en Katalyse, Departement Interfasechemie, K.U. Leuven, \\ Kardinaal Mercierlaan 92, 3001 Heverlee, Belgium
}

Received: February 16, 2001; In Final Form: April 20, 2001

\begin{abstract}
Silica-, alumina-, and zirconia-supported tantalum oxide and supported vanadia-tantala mixed oxide catalysts were investigated by XRD, UV-vis-DR, FTIR, and FT-Raman spectroscopy to determine the nature of the surface tantala species. Two types of surface $\mathrm{TaO}_{x}$ species were identified. On the $\mathrm{SiO}_{2}$ support, at low coverages tetrahedral $\mathrm{TaO}_{4}$ species exist, with a $\mathrm{Ta}=\mathrm{O}$ bond and three bridging $\mathrm{Ta}-\mathrm{O}$-support bonds. At higher coverages, octahedral $\mathrm{TaO}_{6}$ species occur. On $\mathrm{Al}_{2} \mathrm{O}_{3}$ and $\mathrm{ZrO}_{2}$ both surface species exist already at considerably low Ta loading. The acidic properties of the catalysts were investigated by an FTIR study of adsorbed pyridine. Supported tantala is clearly more Lewis acidic in comparison to vanadia. The oxidation of methanol was used to probe the catalytic performance of the supported oxide species and from the activity and product distribution it is concluded that supported tantala predominantly shows acidic over redox behavior.
\end{abstract}

\section{Introduction}

Group V transition metal oxides are very efficient as catalysts in numerous processes. The physical, chemical and catalytic properties of supported vanadium and niobium oxides have been studied extensively in the past, using several spectroscopic characterization techniques and catalytic reactions. Vanadium oxide catalysts catalyze a number of industrially important processes. They have been used successfully in the selective oxidation of aliphatic and aromatic hydrocarbons (e.g., oxidation of methane to formaldehyde, ${ }^{1}$ oxidation of $o$-xylene to phthalic anhydride ${ }^{2-4}$ ), the selective oxidation of $\mathrm{SO}_{2}$ in the production of sulfuric acid, ${ }^{5}$ and the selective catalytic reduction (SCR) of nitric oxide with ammonia ${ }^{6,7}$. In addition, the photocatalytic activity of vanadium oxide catalysts has been reported. ${ }^{8}$ Niobium oxide catalysts exhibit poor performance as redox site during oxidation reactions. ${ }^{9}$ Niobia possesses primarily (Lewis) acidic characteristics. ${ }^{10}$ However, it remarkably enhances the catalytic activity and selectivity of several metal oxide catalysts, when used as additive or support (due to the higher acidity features). ${ }^{11,12}$

Studies on the molecular structure of supported $\mathrm{VO}_{x}$ and $\mathrm{NbO}_{x}$ have revealed that the supported metal oxide phase forms a two-dimensional overlayer on oxide supports such as silica alumina, zirconia, or titania. ${ }^{4}$ There is a general consensus that, at low surface coverages, the vanadia species are present in an isolated tetrahedral $\mathrm{VO}_{4}$ coordination, possessing a terminal $\mathrm{V}=$ $\mathrm{O}$ and three bridging $\mathrm{V}-\mathrm{O}$-support bonds. At higher surface

* To whom correspondence should be addressed. E-mail: baltes@ uia.ua.ac.be.

Laboratory of Adsorption and Catalysis.

Fortum Oil and Gas Oy.

$\S$ Department of Inorganic Chemistry and Catalysis.

"Centrum voor Oppervlaktechemie en Katalyse. vanadia coverages, the vanadia species are polymerized through bridging $\mathrm{V}-\mathrm{O}-\mathrm{V}$ bonds. With increasing surface coverage square pyramidal and octahedrally coordinated (and even crystalline) vanadia species occur. Similarly, supported niobia exhibits $\mathrm{NbO}_{4}$ species at low coverage and polymerized $\mathrm{NbO}_{6}$ species at high coverage. ${ }^{9,13}$

Tantalum oxide is used as optical coating or in electronics technology as capacitor material (because of its high dielectric constant). ${ }^{14-16}$ However, the current knowledge of the physical and chemical properties of tantala is rather limited. Hydrated tantalum oxide $\left(\mathrm{Ta}_{2} \mathrm{O}_{5} \cdot n \mathrm{H}_{2} \mathrm{O}\right)$ is highly acidic. ${ }^{17}$ Ushikubo et al. ${ }^{18,19}$ showed that silica-supported tantalum oxide catalyzes the vapor phase Beckmann rearrangement of cyclohexanone oxime to $\epsilon$-caprolactam. Furthermore, it is reported that $\mathrm{SiO}_{2}-$ $\mathrm{Ta}_{2} \mathrm{O}_{5}$ mixed oxides exhibit unique properties in alcohol dehydration. ${ }^{18,20}$

In this paper, we report on the structural, chemical, and catalytic properties of $\mathrm{SiO}_{2-}, \mathrm{Al}_{2} \mathrm{O}_{3^{-}}$, and $\mathrm{ZrO}_{2}$-supported tantalum oxide catalysts, using the supported vanadium oxide case for comparison. The supported tantala and vanadia catalysts were prepared by liquid- and gas-phase modification reactions starting from tantalum ethoxide $\left(\mathrm{Ta}\left(\mathrm{OC}_{2} \mathrm{H}_{5}\right)_{5}\right)$ and vanadyl acetylacetonate $\left(\mathrm{VO}(\mathrm{acac})_{2}\right)$, respectively. The reaction of the $\mathrm{VO}(\mathrm{acac})_{2}$ complex with various supports has been described in detail in earlier publications. ${ }^{21-27}$ It was demonstrated that the use of transition metal complexes in the preparation of uniform and disperse supported transition metal oxides is very successful. Similarly, Ushikubo et al. ${ }^{19}$ showed that the dispersion and the catalytic performance of the supported tantalum oxide phase is much better when the synthesis is carried out using a tantalum alkoxide rather than by using aqueous impregnation. 
To investigate the $\mathrm{TaO}_{x}$ structure and surface properties, supported vanadia-tantala mixed oxides are prepared as well. The effect of Ta addition on the nature and surface properties of supported vanadia catalysts is discussed. Chemisorption of pyridine followed by IR characterization was applied to study the acidic properties of the catalysts. The oxidation of methanol was performed in order to investigate the redox behavior.

\section{Experimental Section}

The silica (Grace 432), $\gamma$-alumina (AKZO), and zirconia (MEL Chemicals) supports have a specific surface area $\left(S_{\mathrm{BET}}\right)$ of 300,200 , and $59 \mathrm{~m}^{2} / \mathrm{g}$, respectively, after pretreatment in air at $500{ }^{\circ} \mathrm{C}$ for $16 \mathrm{~h}$.

In the liquid phase reactions, the thermally treated support was stirred at room temperature for $1 \mathrm{~h}$ in a zeolite-dried toluene solution containing tantalum ethoxide $\left(\mathrm{Ta}\left(\mathrm{OC}_{2} \mathrm{H}_{5}\right)_{5}\right.$, Fluka) or vanadyl acetylacetonate $\left(\mathrm{VO}(\mathrm{acac})_{2}\right.$, Fluka) for modification with Ta or $\mathrm{V}$, respectively. The reaction vessel was purged with a stream of dry nitrogen. After the reaction the modified support was filtered, washed with fresh solvent and dried under vacuum at room temperature. Subsequently, the samples were calcined in air at $500{ }^{\circ} \mathrm{C}$ for $16 \mathrm{~h}$.

The gas-phase reactions are performed by the Atomic Layer Deposition technique (ALD) ${ }^{28-30}$ The thermally pretreated supports (3 g) were additionally preheated at the reaction temperature for $3 \mathrm{~h}$ in a fixed-bed flow-type reactor, under a pressure of $5-10 \mathrm{kPa}$ in a nitrogen flow. After this pretreatment, the reactant vapors were passed through the support bed, with nitrogen used as carrier gas. Vaporization of the reactants was carried out by sublimation of $\mathrm{VO}(\mathrm{acac})_{2}$ at $160{ }^{\circ} \mathrm{C}$ and evaporation of $\mathrm{Ta}\left(\mathrm{OC}_{2} \mathrm{H}_{5}\right)_{5}$ at $200{ }^{\circ} \mathrm{C}$, respectively. $\mathrm{VO}(\text { acac })_{2}$ was deposited at a reaction temperature of $160{ }^{\circ} \mathrm{C}, \mathrm{Ta}\left(\mathrm{OC}_{2} \mathrm{H}_{5}\right)_{5}$ at $200{ }^{\circ} \mathrm{C}$. After the reaction, the modified support was purged with nitrogen at the reaction temperature for $2 \mathrm{~h}$. Subsequently, calcination was performed in the reactor at $500{ }^{\circ} \mathrm{C}$, in an airflow for 6 h.

The liquid- and gas-phase preparations of the supported vanadia-tantala mixed oxides were carried out similarly, by successive modification of the support (followed by calcination before the next modification).

The Ta and $\mathrm{V}$ concentrations were determined by electron microprobe analysis and neutron activation analysis. In the liquid-phase modification, samples were prepared with varying metal loading (up to $0.8 \mathrm{mmol} / \mathrm{g}$ Ta and up to $1.0 \mathrm{mmol} / \mathrm{g} \mathrm{V}$ ), by using appropriate amounts of the transition metal precursors in the reaction solution. In the gas-phase modification, one reaction cycle was performed (i.e., deposition of the precursor until saturation of the support and subsequent calcination), which leads to $\mathrm{V}$ and $\mathrm{Ta}$ coverages listed in Table 1. The actual deposition process is discussed in detail in earlier publications. ${ }^{21-25,28-30}$

Pyridine adsorption was performed after calcination of the samples at $500{ }^{\circ} \mathrm{C}$ for $16 \mathrm{~h}$, and subsequent degassing at 150 ${ }^{\circ} \mathrm{C}$ for $3 \mathrm{~h}$. The samples were exposed to pyridine vapor for 30 min. After evacuation for $3 \mathrm{~h}$ at $150{ }^{\circ} \mathrm{C}$, the FTIR-PAS spectra were recorded.

Photoacoustic infrared spectra (FTIR-PAS) were measured on a Nicolet 20 SX spectrometer, equipped with a McClelland Photoacoustic cell. X-ray diffraction patterns were collected on a Philips PW1840 powder diffractometer (45 kV, $30 \mathrm{~mA}$ ), using Ni-filtered $\mathrm{CuK} \alpha$ radiation. $\mathrm{UV}-$ vis diffuse reflectance spectra (UV-vis-DRS) were obtained on a UNICAM 8700 UV-vis spectrometer, with a diffuse reflectance accessory using $\mathrm{BaSO}_{4}$ standard white as reference. FT-Raman spectra were recorded
TABLE 1: Ta and V Loading of the Liquid Phase and Gas Phase Prepared Supported Oxide Catalysts

\begin{tabular}{|c|c|c|c|c|}
\hline \multirow[b]{2}{*}{ catalyst } & \multicolumn{2}{|c|}{$\begin{array}{l}\text { liquid-phase } \\
\text { modification }\end{array}$} & \multicolumn{2}{|c|}{$\begin{array}{l}\text { gas-phase } \\
\text { modification }\end{array}$} \\
\hline & $\begin{array}{l}\text { V loading } \\
(\mathrm{mmol} / \mathrm{g})\end{array}$ & $\begin{array}{l}\text { Ta loading } \\
(\mathrm{mmol} / \mathrm{g})\end{array}$ & $\begin{array}{l}\text { V loading } \\
(\mathrm{mmol} / \mathrm{g})\end{array}$ & $\begin{array}{l}\text { Ta loading } \\
(\mathrm{mmol} / \mathrm{g})\end{array}$ \\
\hline $\mathrm{VO}_{x} / \mathrm{SiO}_{2}$ & up to 1.00 & & 0.49 & \\
\hline $\mathrm{VO}_{x} / \mathrm{Al}_{2} \mathrm{O}_{3}$ & up to 2.00 & & 0.91 & \\
\hline $\mathrm{VO}_{x} / \mathrm{ZrO}_{2}$ & up to 1.00 & & 0.31 & \\
\hline $\mathrm{TaO}_{x} / \mathrm{SiO}_{2}$ & & up to 0.80 & & 0.48 \\
\hline $\mathrm{TaO}_{x} / \mathrm{Al}_{2} \mathrm{O}_{3}$ & & up to 0.80 & & 0.55 \\
\hline $\mathrm{TaO}_{x} / \mathrm{ZrO}_{2}$ & & up to 0.60 & & 0.16 \\
\hline $\mathrm{VO}_{x}-\mathrm{TaO}_{x} / \mathrm{SiO}_{2}$ & up to 1.00 & up to 0.80 & 0.51 & 0.54 \\
\hline $\mathrm{VO}_{x}-\mathrm{TaO}_{x} / \mathrm{Al}_{2} \mathrm{O}_{3}$ & up to 2.00 & up to 0.80 & 0.87 & 0.34 \\
\hline $\mathrm{VO}_{x}-\mathrm{TaO}_{x} / \mathrm{ZrO}_{2}$ & up to 1.00 & up to 0.60 & 0.29 & 0.15 \\
\hline
\end{tabular}

on a Nicolet Nexus FT-Raman spectrometer with a Ge detector. All samples were measured at room temperature in a 180 degree reflective sampling configuration, with a $1064 \mathrm{~nm} \mathrm{Nd:YAG}$ excitation laser.

The oxidation of methanol was carried out at $250{ }^{\circ} \mathrm{C}$ in a fixed-bed continuous flow reactor at atmospheric pressure. The amount of catalyst was controlled to obtain less than $10 \%$ methanol conversion. Prior to the reaction the catalyst was treated by flowing a $\mathrm{He} / \mathrm{O}_{2}$ mixture at $400{ }^{\circ} \mathrm{C}$ for $16 \mathrm{~h}$, to remove physisorbed water. A $100 \mathrm{~mL} / \mathrm{min} \mathrm{He} / \mathrm{O}_{2} / \mathrm{MeOH}(88 /$ $8 / 4$ mol \%) flow was used as reactant mixture. Reaction products were analyzed by gas chromatography on a $2 \mathrm{~m} \times 1 / 8$ in. Porapak T column (Alltech Inc.).

\section{Results}

(1) Structural Characterization. (A) XRD. X-ray diffraction analysis was performed on the support materials and on the supported oxide catalysts. The silica and alumina supports are amorphous, whereas the zirconia support shows various reflections typical for the monoclinic crystal structure. The catalysts demonstrate a featureless XRD pattern, except for the characteristic pattern of the respective support materials, which suggests that the deposited oxide layers are amorphous.

(B) UV-Vis Diffuse Reflectance Spectroscopy. UV-vis-DRS is used to investigate the coordination of the supported oxide species, since the energy of the oxygen-to-metal charge transfer (CT) bands is dependent on the transition metal ion and on the number of oxygen atoms surrounding it. Therefore, UV-visDRS allows to distinguish between different types of transition metal oxide configurations present on the support. Supported vanadium oxides generally show several CT bands as a function of the vanadium loading, according to the presence of three main types of configurations: ${ }^{25,31,32}$ tetrahedrally coordinated monomers and polymeric chains (characterized by CT bands between 200 and $400 \mathrm{~nm}$ ), two-dimensional ribbons with a square pyramid coordination geometry (CT band at $410 \mathrm{~nm}$ ) and octahedrally coordinated species (CT band at $470 \mathrm{~nm}$ ). Figure 1 shows the UV-vis-DRS spectra of the tantalum oxide containing catalysts, prepared by liquid phase and gas phase. Pure $\mathrm{Ta}_{2} \mathrm{O}_{5}$ (where the central $\mathrm{Ta}^{5+}$ ion is in a octahedral configuration) shows a main absorption band at $\sim 270 \mathrm{~nm}$.

(i) $\mathrm{SiO}_{2}$. Silica-supported tantala (Figure 1A) exhibits at low loading $(<0.5 \mathrm{mmol} / \mathrm{g} \mathrm{Ta})$ a strong band with maximum at 233 $\mathrm{nm}$ (Figure 1A, spectrum a). With higher loadings an additional band is present at $265 \mathrm{~nm}$, and some absorption appears in the 300-350 nm region (spectrum b). Remarkably, the samples prepared by the ALD technique show better uniformity compared to the liquid-phase samples. The $\mathrm{TaO}_{x} / \mathrm{SiO}_{2}$ sample in 

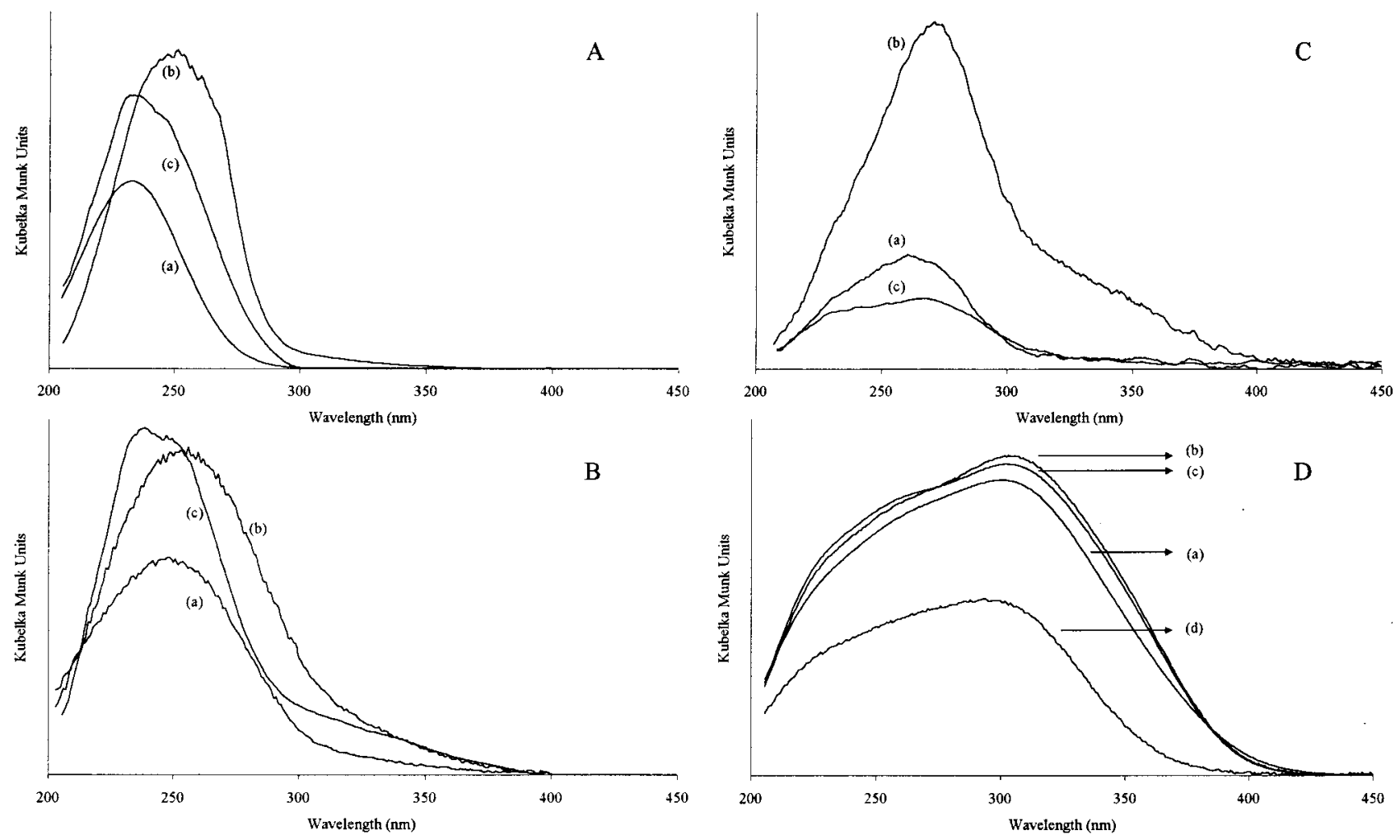

Figure 1. UV-vis diffuse reflectance spectra of the supported oxide catalysts. (A) $\mathrm{TaO}_{x} / \mathrm{SiO}_{2}$ catalysts; (a) liquid-phase sample $0.21 \mathrm{mmol} / \mathrm{g}$; (b) liquid-phase sample $0.47 \mathrm{mmol} / \mathrm{g}$; (c) ALD sample $0.48 \mathrm{mmol} / \mathrm{g}$. (B) $\mathrm{TaO}_{x} / \mathrm{Al}_{2} \mathrm{O}_{3}$ catalysts; (a) liquid-phase sample $0.20 \mathrm{mmol} / \mathrm{g}$; (b) liquid-phase sample $0.80 \mathrm{mmol} / \mathrm{g}$; (c) ALD sample $0.55 \mathrm{mmol} / \mathrm{g}$. (C) $\mathrm{TaO}_{x} / \mathrm{ZrO}_{2}$ catalysts measured with zirconia as reference; (a) liquid-phase sample 0.15 $\mathrm{mmol} / \mathrm{g}$; (b) liquid-phase sample $0.60 \mathrm{mmol} / \mathrm{g}$; (c) ALD sample $0.16 \mathrm{mmol} / \mathrm{g}$. (D) Liquid phase prepared $\mathrm{VO}_{x}-\mathrm{TaO}_{x} / \mathrm{SiO}_{2}$ catalysts with respective loadings of (a) $0.36 \mathrm{mmol} / \mathrm{g} \mathrm{V}$ and $0 \mathrm{mmol} / \mathrm{g} \mathrm{Ta}$; (b) $0.36 \mathrm{mmol} / \mathrm{g} \mathrm{V}$ and $0.20 \mathrm{mmol} / \mathrm{g} \mathrm{Ta}$; (c) $0.35 \mathrm{mmol} / \mathrm{g} \mathrm{V}$ and $0.59 \mathrm{mmol} / \mathrm{g} \mathrm{Ta}$; (d) $0.20 \mathrm{mmol} / \mathrm{g}$ $\mathrm{V}$ and $0.60 \mathrm{mmol} / \mathrm{g}$ Ta.

Figure 1A, spectrum c, shows almost exclusive absorption at $233 \mathrm{~nm}$, whereas the liquid-phase sample with the same loading already exhibits absorption at higher wavelengths.

(ii) $\mathrm{Al}_{2} \mathrm{O}_{3}$. Alumina-supported tantala (Figure 1B) also shows the CT band around $230 \mathrm{~nm}$, but it already exhibits an absorption at higher wavelengths $(265 \mathrm{~nm})$ at considerably low loadings, even in the case of the ALD-prepared samples.

(iii) $\mathrm{ZrO}_{2}$. The pure zirconia support is not transparent in the UV region studied. Therefore it is difficult to infer unambiguous information. However, when the UV-vis-DRS spectra are obtained with the zirconia support as reference (Figure 1C), similar bands with maxima around 235 and $270 \mathrm{~nm}$ are observed.

(iv) $V O_{x}-T_{a} O_{x}$. The spectra of the supported vanadiumtantalum mixed oxides (in Figure 1D, the silica-supported catalysts are presented) show the same evolution as the spectra obtained for supported vanadium oxides. Increasing the vanadium concentration (with constant Ta concentration) results in typical charge-transfer transitions at higher wavelength, which shows that more polymerized $\mathrm{VO}_{x}$ species occur. However, increasing the Ta concentration (Figure 1D, spectra $a-c$ ) does not result in an appreciable change of the UV-vis-DRS spectra. In addition, there is no change when the sequence of grafting of vanadium oxide and tantalum oxide is reversed.

Figure 2 presents the UV-vis-DRS spectra of supported vanadia and tantala after hydration of the catalysts. Hydration (or exposure to ambient conditions) dramatically changes the molecular structure of the surface species, due to coordination of water molecules. In the case of supported vanadium oxide, these changes are easily observable, as the dehydrated white samples turn yellow or orange upon exposure to ambient air. Therefore, the UV-vis-DRS spectra of the hydrated vanadium oxide samples show significant absorption in the 400-600 nm region (Figure 2A). Hydration of the white supported tantala samples does not result in a change of color. Still, the hydrated tantala samples in Figure 2B show an increased absorption of the CT band around $260 \mathrm{~nm}$ and in the $300-350 \mathrm{~nm}$ region, suggesting a similar change of the $\mathrm{TaO}_{x}$ structures, due to the coordination of water.

(C) FTIR Spectroscopy. (i) OH Stretching Region. Infrared spectroscopy yields information on the interaction of the surface metal oxide species with the support, by examining the surface hydroxyl region. After the modification with $\mathrm{TaO}_{x}$ and/or $\mathrm{VO}_{x}$, the IR intensity of the various $\mathrm{OH}$ bands of the $\mathrm{SiO}_{2}, \mathrm{Al}_{2} \mathrm{O}_{3}$, and $\mathrm{ZrO}_{2}$ supports decreases gradually with increasing loading, due to the consumption of the surface hydroxyls in the reaction with the respective transition metal precursors. Accordingly, the deposited oxide is linked to the support by support-oxygenmetal bonds. However, even at considerably high coverages, not all the surface $\mathrm{OH}$ groups are removed. On $\mathrm{SiO}_{2}$, with increasing $\mathrm{V}$ and Ta coverage new bands appear at 3660 or $3680 \mathrm{~cm}^{-1}$ (spectra not shown), revealing the presence of $\mathrm{V}-\mathrm{OH}^{25}$ and $\mathrm{Ta}-\mathrm{OH}^{17}$ species, respectively. In the case of the alumina and zirconia-supported vanadia and tantala samples the interpretation of the appearance of these metal- $\mathrm{OH}$ species is difficult because of the IR bands of the support hydroxyls. However, at higher Ta loadings an increased intensity is observed of a band located at $3743 \mathrm{~cm}^{-1}$, attributed to new $\mathrm{OH}$ groups generated on these samples.

(ii) Metal-Oxygen Region. The infrared spectra also show important vanadium-oxygen and tantalum-oxygen IR vibrations. Unfortunately, some of the metal-oxygen vibrations are obscured by the overlapping IR bands of the various supports. 

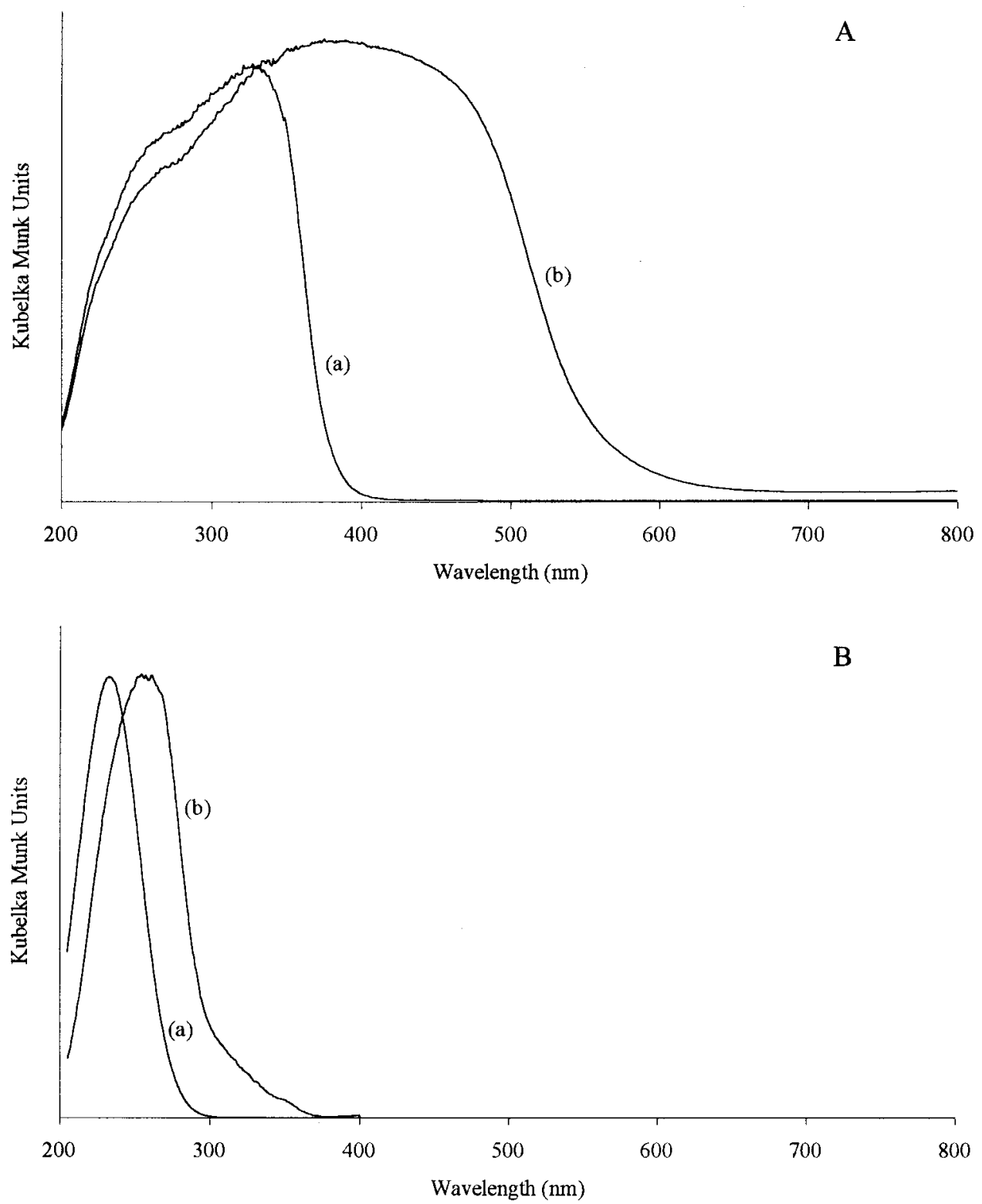

Figure 2. Influence of hydration on the structure of the supported oxide catalysts. UV-vis diffuse reflectance $\mathrm{spectra}$ of $\mathrm{VO}_{x} / \mathrm{SiO}_{2}(\mathrm{~A})$ and $\mathrm{TaO}_{x} /$ $\mathrm{SiO}_{2}$ (B) in the dehydrated (a) and hydrated (b) state.

In Figure 3, the IR spectra of the metal-oxygen region of the catalysts under study are shown. To clarify the occurring metaloxygen species in the case of the alumina and zirconia-supported samples, difference spectra are presented after spectrum subtraction of the blank supports.

(a) $\mathrm{SiO}_{2}$. In the case of the silica-supported vanadium oxide catalysts (Figure 3A, spectrum b), a band around $926 \mathrm{~cm}^{-1}$ is attributed to the presence of $\mathrm{Si}-\mathrm{O}-\mathrm{V}$ bonds. ${ }^{25}$ Both liquid- and gas-phase-prepared $\mathrm{TaO}_{x} / \mathrm{SiO}_{2}$ samples show broad bands centered around 702 and $918 \mathrm{~cm}^{-1}$ (Figure 3A, spectrum c). The former corresponds to $\mathrm{Ta}-\mathrm{O}$ stretching vibration modes. ${ }^{33}$ The latter can be attributed to the presence of $\mathrm{Si}-\mathrm{O}-\mathrm{Ta}$ linkages in accordance to the vanadia case. Additionally, a clearly resolved band is observed at $976 \mathrm{~cm}^{-1}$.

(b) $\mathrm{Al}_{2} \mathrm{O}_{3}$. The $\mathrm{VO}_{x} / \mathrm{Al}_{2} \mathrm{O}_{3}$ samples (Figure $3 \mathrm{~B}$, spectrum a) show an IR absorption at $1025 \mathrm{~cm}^{-1}$, assigned to the symmetric stretching vibration of terminal $\mathrm{V}=\mathrm{O}^{32,34}$ with three bridging $\mathrm{V}-\mathrm{O}-\mathrm{Al}$ linkages to the support surface. $\mathrm{TaO}_{x} / \mathrm{Al}_{2} \mathrm{O}_{3}$ exhibits a band at $980 \mathrm{~cm}^{-1}$. Remarkably, at higher Ta coverages (spectrum c) an absorption is observed at $2336 \mathrm{~cm}^{-1}$. This is assigned to a stretching vibration mode of $\mathrm{Ta}=\mathrm{O}$ bonds in an amorphous tantalum oxide overlayer. ${ }^{35}$ It is located at $2335 \mathrm{~cm}^{-1}$ when an amorphous tantala phase is formed, and is shifted to $2340 \mathrm{~cm}^{-1}$ in crystalline tantala. The $\mathrm{OH}$ band at $3743 \mathrm{~cm}^{-1}$ which is generated simultaneously with the formation of this amorphous tantala layer, can therefore be attributed to $\mathrm{Ta}-\mathrm{OH}$ species on the amorphous overlayer.

(c) $\mathrm{ZrO}_{2}$. Zirconia-supported vanadia samples (Figure 3C, spectrum a) show an IR absorption at $1024 \mathrm{~cm}^{-1}$, which can also be assigned to terminal $\mathrm{V}=\mathrm{O} \cdot{ }^{36}$ However, a band around $850-820 \mathrm{~cm}^{-1}$ is observed, which indicates the presence of $\mathrm{V}-\mathrm{O}-\mathrm{V}$ linkages. In contrast to silica and alumina, the zirconiasupported tantala (Figure 3, spectrum b) only shows a minor band at $980 \mathrm{~cm}^{-1}$ and a broad contribution of $\mathrm{Ta}-\mathrm{O}$ vibrations is observed around $820 \mathrm{~cm}^{-1}$. At higher Ta coverages, the presence of the $2336 \mathrm{~cm}^{-1}$ band reveals the formation of an amorphous tantala phase, similar to the alumina case.

(d) $\mathrm{VO}_{x}-\mathrm{TaO}_{x}$. The supported vanadia-tantala mixed oxide samples exhibit several bands of both the vanadia and tantala, showing the same evolution as a function of the loading as in the case of the supported oxides as such. When vanadia is deposited on the alumina- and zirconia-supported tantala 


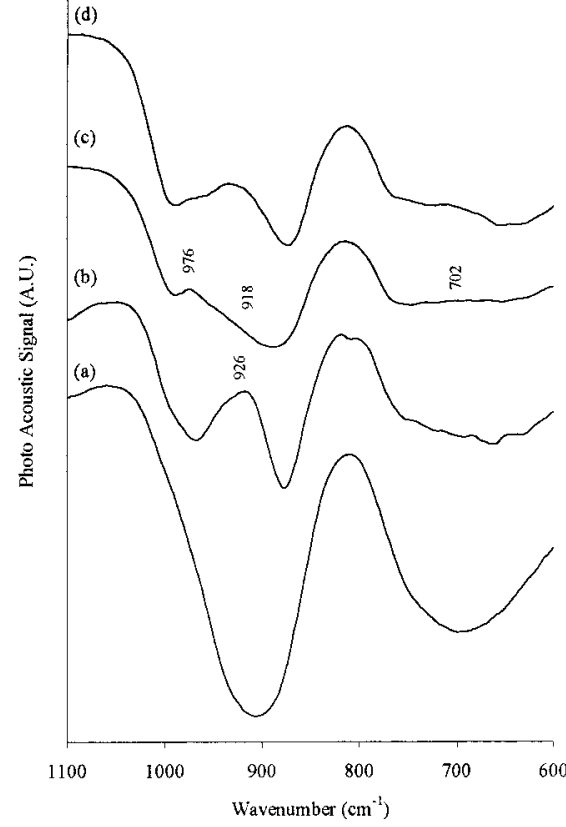

A

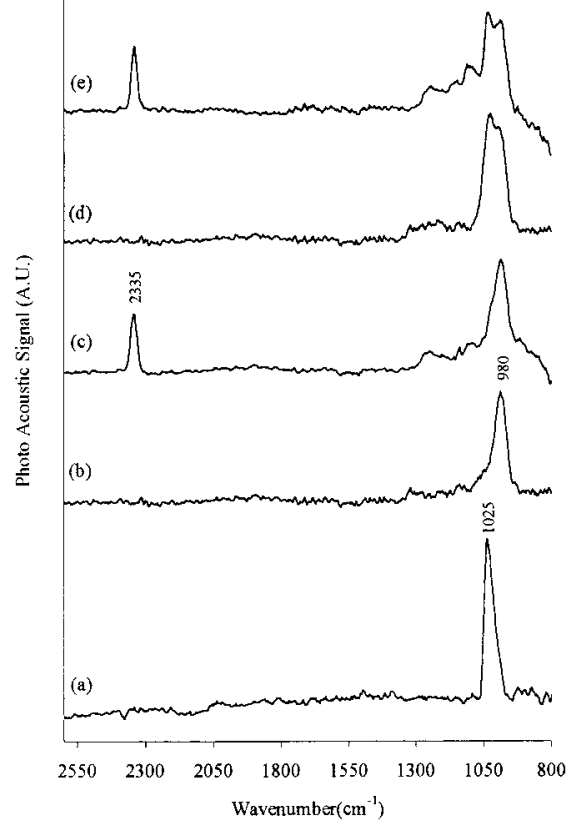

B

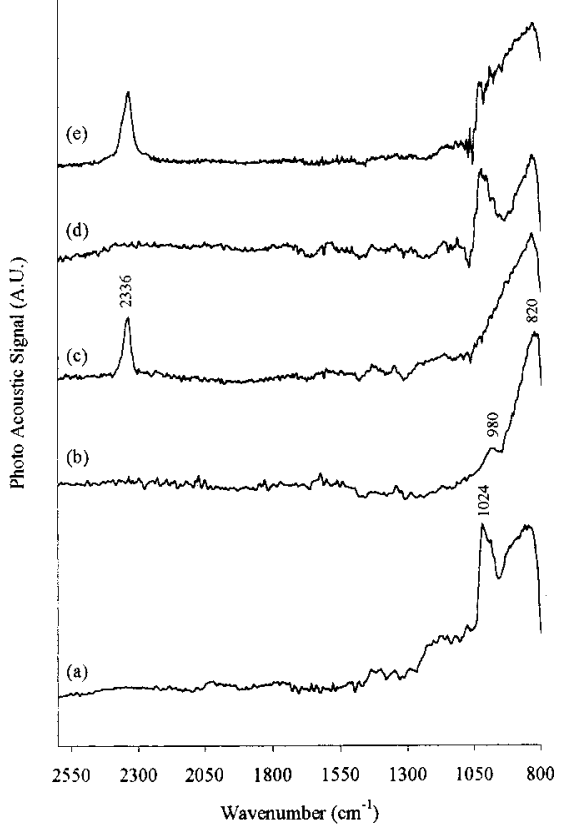

$\mathrm{C}$

Figure 3. FTIR-PAS spectra of the liquid phase prepared supported oxide catalysts studied in the metal oxygen region. (A) Silica-supported oxide catalysts (a) pure $\mathrm{SiO} 2$ support after pretreatment at $500{ }^{\circ} \mathrm{C}$; (b) $\mathrm{VO}_{x} / \mathrm{SiO}_{2}(0.36 \mathrm{mmol} / \mathrm{g}) ;$ (c) $\mathrm{TaO}_{x} / \mathrm{SiO}_{2}(0.47 \mathrm{mmol} / \mathrm{g}) ;(\mathrm{d}) \mathrm{VO}_{x}-\mathrm{TaO}_{x} / \mathrm{SiO}_{2}$ with respective $\mathrm{V}$ and Ta loading of 0.35 and $0.20 \mathrm{mmol} / \mathrm{g}$. (B) difference spectra of the alumina-supported oxide catalysts; after spectrum subtraction of blank alumina. (a) $\mathrm{VO}_{x} / \mathrm{Al}_{2} \mathrm{O}_{3}\left(0.70 \mathrm{mmol} / \mathrm{g}\right.$ ); (b) $\mathrm{TaO}_{x} / \mathrm{Al}_{2} \mathrm{O}_{3}\left(0.20 \mathrm{mmol} / \mathrm{g}\right.$ ); (c) $\mathrm{TaO}_{x} / \mathrm{Al}_{2} \mathrm{O}_{3}\left(0.80 \mathrm{mmol} / \mathrm{g}\right.$ ); (d) $\mathrm{VO}_{x}-\mathrm{TaO}_{x} / \mathrm{Al}_{2} \mathrm{O}_{3}$ with respective $\mathrm{V}$ and Ta loading of 0.72 and $0.45 \mathrm{mmol} / \mathrm{g}$; (e) $\mathrm{VO}_{x}-\mathrm{TaO}_{x} / \mathrm{Al}_{2} \mathrm{O}_{3}$ with respective $\mathrm{V}$ and Ta loading of 0.69 and $0.78 \mathrm{mmol} / \mathrm{g}$. C: difference spectra of the zirconia-supported oxide catalysts; after spectrum subtraction of blank zirconia. (a) $\mathrm{VO}_{x} / \mathrm{ZrO}_{2}(0.37 \mathrm{mmol} / \mathrm{g})$; (b) $\mathrm{TaO} x / \mathrm{ZrO} 2(0.24 \mathrm{mmol} / \mathrm{g})$; (c) $\mathrm{TaO}_{x} / \mathrm{ZrO}_{2}(0.60 \mathrm{mmol} / \mathrm{g})$; (d) $\mathrm{VO}_{x}-\mathrm{TaO}_{x} / \mathrm{ZrO}_{2}$ with respective $\mathrm{V}$ and $\mathrm{Ta}$ loading of 0.37 and $0.34 \mathrm{mmol} / \mathrm{g}$; (e) $\mathrm{VO}_{x}-\mathrm{TaO}_{x} / \mathrm{ZrO}_{2}$ with respective $\mathrm{V}$ and Ta loading of 0.37 and $0.57 \mathrm{mmol} / \mathrm{g}$.

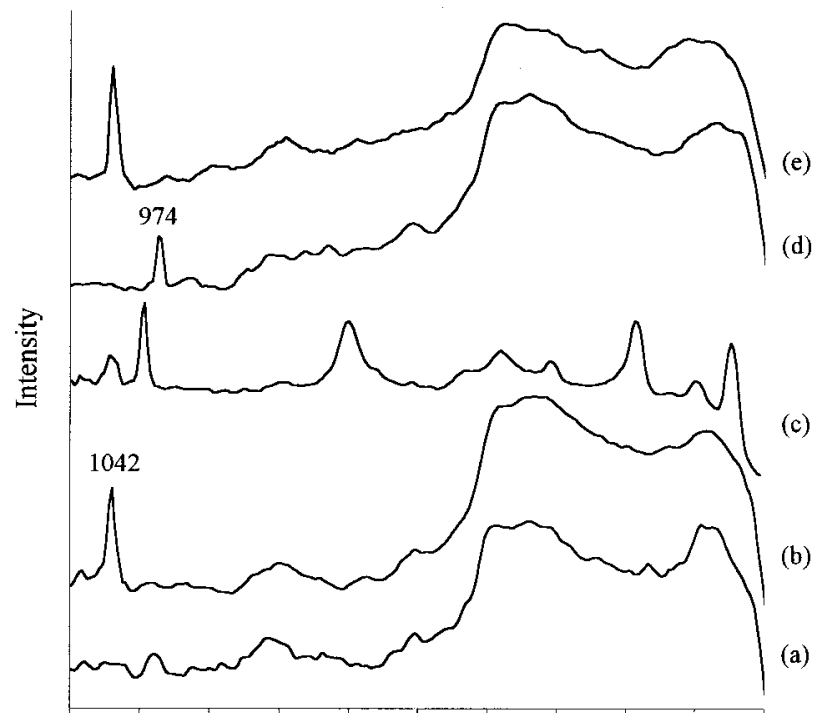

\section{$11001000 \quad 900 \quad 800 \quad 700 \quad 600 \quad 500 \quad 400 \quad 300 \quad 200 \quad 100$ Raman Shift $\left(\mathrm{cm}^{-1}\right)$}

Figure 4. FT-Raman spectra of the silica-supported oxide catalysts; (a) pure $\mathrm{SiO}_{2}$; (b) $\mathrm{VO}_{x} / \mathrm{SiO}_{2}(0.36 \mathrm{mmol} / \mathrm{g})$; (c) $\mathrm{VO}_{x} / \mathrm{SiO}_{2}(1.03 \mathrm{mmol} /$ g); (d) $\mathrm{TaO}_{x} / \mathrm{SiO}_{2}(0.47 \mathrm{mmol} / \mathrm{g})$; (e) $\mathrm{VO}_{x}-\mathrm{TaO}_{x} / \mathrm{SiO}_{2}$ with respective $\mathrm{V}$ and Ta loading of 0.35 and $0.59 \mathrm{mmol} / \mathrm{g}$.

samples, which already exhibit the amorphous tantalum oxide phase, it is observed that the intensity of the $3743 \mathrm{~cm}^{-1}$ band $(\mathrm{Ta}-\mathrm{OH})$ decreases. This suggests that a part of the vanadia species is linked to the tantala species.

(D) Raman Spectroscopy. Figures 4 and 5 show the FTRaman spectra of the modified silica and zirconia samples. Unfortunately, the interpretation of the alumina-supported sam-

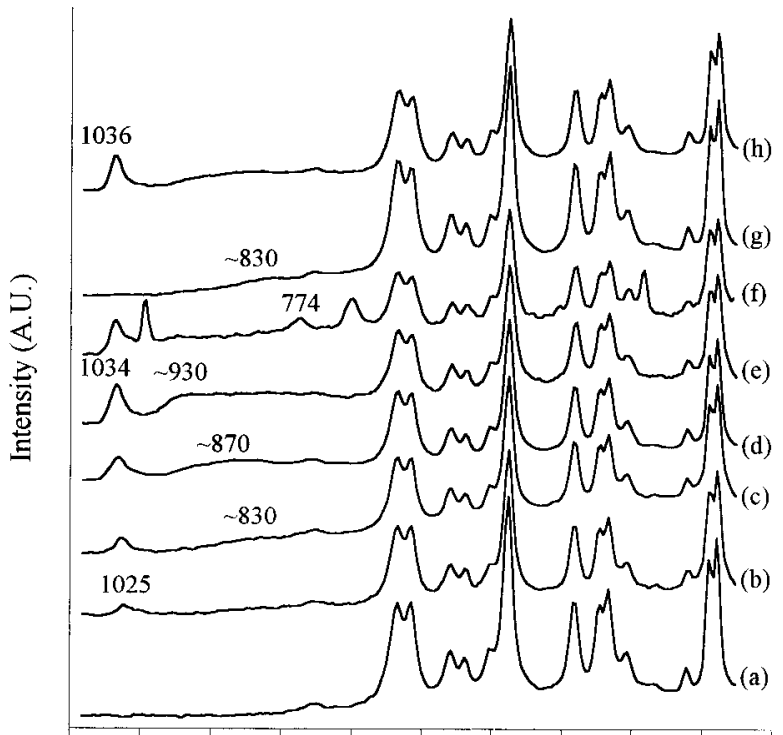

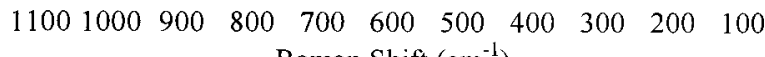
Raman Shift $\left(\mathrm{cm}^{-1}\right)$

Figure 5. FT-Raman spectra of the zirconia-supported oxide catalysts; (a) pure $\mathrm{ZrO}_{2} ;(\mathrm{b}-\mathrm{f}) \mathrm{VO}_{x} / \mathrm{ZrO}_{2}$ with respective $\mathrm{V}$ loading of 0.09 , $0.19,0.37,0.62$, and $1.02 \mathrm{mmol} / \mathrm{g} ;(\mathrm{g}) \mathrm{TaO}_{x} / \mathrm{ZrO}_{2}(0.24 \mathrm{mmol} / \mathrm{g})$; (h) $\mathrm{VO}_{x}-\mathrm{TaO}_{x} / \mathrm{ZrO}_{2}$ with respective $\mathrm{V}$ and $\mathrm{Ta}$ loading of 0.37 and 0.34 $\mathrm{mmol} / \mathrm{g}$.

ples is complicated by a broad fluorescence background which overshadows the Raman features of the surface oxide species.

(i) $\mathrm{SiO}_{2}$. Pure silica exhibits Raman modes at 430, 488, 605, 800 , and $980 \mathrm{~cm}^{-1}$ (Figure 4a). Silica-supported vanadia in Figure $4 \mathrm{~b}$ exhibits a strong Raman band at $1042 \mathrm{~cm}^{-1}$, assigned to the stretching mode of $\mathrm{V}=\mathrm{O}$ in a tetrahedral species with 
three $\mathrm{V}-\mathrm{O}-\mathrm{Si}$ bonds to the silica surface. ${ }^{25,32}$ At $\mathrm{V}$ loadings of $>0.6 \mathrm{mmol} / \mathrm{g}$, strong Raman features at 994, 697, 286, and $147 \mathrm{~cm}^{-1}$ (Figure 4c) reveal the formation of crystalline $\mathrm{V}_{2} \mathrm{O}_{5}$ (the XRD patterns could not evidence the presence of $\mathrm{V}_{2} \mathrm{O}_{5}$, which means that Raman spectroscopy is much more sensitive to small crystalline clusters). Silica-supported tantala (Figure 4d) shows a band at $974 \mathrm{~cm}^{-1}$. The infrared study also showed a distinct band around $976 \mathrm{~cm}^{-1}$. These bands are probably arising from $\mathrm{Ta}=\mathrm{O}$ vibrations. Samples with $\mathrm{Ta}$ loadings of up to $0.8 \mathrm{mmol} / \mathrm{g}$ still show no bands of crystalline $\mathrm{Ta}_{2} \mathrm{O}_{5}$ (Raman bands ${ }^{26,37}$ at 105,253 , and $627 \mathrm{~cm}^{-1}$ ).

(ii) $\mathrm{ZrO}_{2}$. The spectrum of the monoclinic zirconia sample has several strong bands at 634, 616, 476, 382, 334, 190, and $179 \mathrm{~cm}^{-1}$ (Figure 5a). Due to the influence of the oxide support the surface vanadium oxide band positions are shifted in comparison to the spectra of the silica-supported vanadia samples. On zirconia, the characteristic $\mathrm{V}=\mathrm{O}$ band is observed at $1025 \mathrm{~cm}^{-1}$ (Figure 5b). Upon higher loadings, this band is gradually shifted to $1034 \mathrm{~cm}^{-1}$ (Figures $5 \mathrm{c}-\mathrm{e}$ ). In addition, broad bands appear around $830 \mathrm{~cm}^{-1}$ for low V loadings (Figure $5 \mathrm{c}$ ), and at $\sim 870$ and $\sim 930 \mathrm{~cm}^{-1}$ for higher $\mathrm{V}$ loadings (Figure 5 , panels d and e). At low loadings, the Raman features indicate dispersed vanadia species. The bands at 1025 and $820 \mathrm{~cm}^{-1}$ are assigned to orthovanadate-like species in a tetrahedral coordination. The shift of the $\mathrm{V}=\mathrm{O}$ band to higher values and the appearance of the $870 \mathrm{~cm}^{-1}$ band are due to the presence of dimeric or pyrovanadate-like $\left(\mathrm{V}_{2} \mathrm{O}_{7}\right)$ species. At even higher coverages, the broad band around $930 \mathrm{~cm}^{-1}$ indicates the formation of polymerized surface vanadium oxide species, linked to each other by $\mathrm{V}-\mathrm{O}-\mathrm{V}$ bridges. At a $\mathrm{V}$ loading of 1 $\mathrm{mmol} / \mathrm{g}$ (Figure 5f), bands at 994, 701, and 408 reveal the formation of $\mathrm{V}_{2} \mathrm{O}_{5}$ and a band at 774 shows the presence of a small $\mathrm{ZrV}_{2} \mathrm{O}_{7}$ phase, which is due to zirconia migration into the $\mathrm{V}_{2} \mathrm{O}_{5}$ crystallites. ${ }^{38}$ Remarkably, samples up to a loading of $0.7 \mathrm{mmol} / \mathrm{g}$ (spectrum 5e) exhibit no bands indicative of the formation of $\mathrm{ZrV}_{2} \mathrm{O}_{7}$. Many other investigations already observe a quite strong $\mathrm{ZrV}_{2} \mathrm{O}_{7}$ band at intermediate loadings. ${ }^{27,39}$ It demonstrates that the preparation method starting form VO$(\mathrm{acac})_{2}$ is beneficial in the creation of highly dispersed supported vanadium oxides.

The zirconia-supported tantala (Figure $5 \mathrm{~g}$ ) shows a broad Raman feature around $830 \mathrm{~cm}^{-1}$. The intensity of this band increases with higher loadings. It is attributed to the surface oxide species linked to eachother by $\mathrm{Ta}-\mathrm{O}-\mathrm{Ta}$ species. The infrared study of the supported tantala samples at quite high coverages showed the presence of an amorphous $\mathrm{Ta}_{2} \mathrm{O}_{5}$ phase (IR band at $2335 \mathrm{~cm}^{-1}$ ). The presence of microcrystalline tantalum oxide clusters, however, cannot be inferred from the Raman spectra due to the strong bands of the zirconia support.

(iii) $\mathrm{VO}_{x}-\mathrm{TaO}_{x}$. The spectra of the supported vanadia-tantala mixed oxide catalysts (Figure $4 \mathrm{e}$ and Figure $5 \mathrm{~h}$ ) are similar to the supported vanadia samples. Suprisingly, they show no Raman features arising from the tantala phase. This is probably due to the low cross-section of the tantalum-oxygen vibrations compared to the vanadium-oxygen vibrations, as reported for the niobia-vanadia system. ${ }^{11}$ No changes in the Raman spectra are observed upon addition of tantalum oxide to the silicasupported vanadia samples, nor when the vanadia phase is deposited on a previously prepared silica-supported tantala phase (the $\mathrm{V}=\mathrm{O}$ band is observed at $1042 \mathrm{~cm}^{-1}$ ). In the case of the zirconia samples (Figure $5 \mathrm{~h}$ ), the $\mathrm{V}=\mathrm{O}$ band is somewhat shifted to higher values upon addition of tantala, but there is no gradual change with increasing Ta loading. In addition, the vanadiatantala samples exhibit no bands attributed to polymeric
$\mathrm{V}-\mathrm{O}-\mathrm{V}$ species (at $930 \mathrm{~cm}^{-1}$ ), which means that the vanadia phase rests well-dispersed over the support surface and is not forced to aggregate upon Ta addition.

(2) Surface Properties. (A) Acidic Properties: Adsorption of Pyridine. The spectroscopic study of adsorbed pyridine is a useful method to determine the catalysts' surface acidity, as it enables to distinguish between Brønsted and Lewis acid sites. The type of interaction between the adsorbed pyridine and the acid sites on the catalyst surface gives rise to several characteristic infrared bands.

Typical IR absorption bands of pyridine adsorbed on Brønsted acid sites (BPy) are found around 1491, 1545, 1578, and 1640 $\mathrm{cm}^{-1}$, whereas Lewis acidity gives rise to pyridine bands (LPy) around 1450, 1491, 1578, and $1612 \mathrm{~cm}^{-1} \cdot 10,40-42$ The ratio of the areas under the bands around $1545 \mathrm{~cm}^{-1}$ (BPy) and 1450 $\mathrm{cm}^{-1}$ (LPy) is usually related to the ratio of concentrations of Brønsted to Lewis acidity (B/L) ${ }^{41}$ The exact positions of the 1450 and $1612 \mathrm{~cm}^{-1}$ LPy bands are sensitive to the strength of the Lewis acidity.

Figure 6 presents the infrared spectra of the supports and supported metal oxides under study, after adsorption of pyridine and degassing at $150{ }^{\circ} \mathrm{C}$ (in order to avoid the presence of physisorbed pyridine). $\mathrm{SiO}_{2}$ exposed to pyridine vapor (Figure $6 \mathrm{~A}$, spectrum a) shows no characteristic bands of the adsorbed base, indicating that the silica surface exhibits no Brønsted nor Lewis acidity. In contrast, alumina contains strong Lewis acid sites, giving rise to LPy bands at 1449, 1491 and $1614 \mathrm{~cm}^{-1}$ (Figure 6B, spectrum a). The infrared spectrum of the zirconia support after adsorption of pyridine (Figure 6C, spectrum a), shows bands at 1445,1488 , and $1608 \mathrm{~cm}^{-1}$, attributed to Lewis acidity. In addition, a small contribution at $1542 \mathrm{~cm}^{-1}$ indicates the presence of Brønsted sites (surface $\mathrm{OH}$ groups). From the position of the LPy bands it is inferred that the Lewis sites on zirconia are clearly weaker than the Lewis sites on alumina.

The supported vanadium oxide shows bands typical of both Lewis and Brønsted acidity. Supported tantalum oxide catalysts exhibits only LPy bands at low coverages. At higher Ta loadings Brønsted acidity occurs as well (in accordance with the formation of $\mathrm{Ta}-\mathrm{OH}$ species at higher loadings, see infrared discussion above). Still, from the Brønsted-to-Lewis ratio (B/ L) obtained after integration of the bands around $1545 \mathrm{~cm}^{-1}$ (BPy) and $1450 \mathrm{~cm}^{-1}$ (Lpy) (presented in Table 2), it can be inferred that the supported tantala samples exhibit more Lewis acidity in comparison to supported vanadia. In addition, the supported vanadia-tantala mixed oxides show an increased Lewis acidity (B/L decreases), with increasing Ta content. Clearly, supported tantalum oxide exhibits predominantly Lewis acidic characteristics. Furthermore, the position of the LPy bands indicate, that the Lewis acid sites on the surface of the silica and alumina-supported tantala catalysts are stronger than the Lewis acid sites on $\mathrm{TaO}_{x} / \mathrm{ZrO}_{2}$.

(B) Catalytic Performance in the Oxidation of Methanol. The oxidation of methanol is a useful test reaction to study the redox behavior of the supported oxide catalysts. It is commonly used as a catalytic surface probe, as it leads to various products according to the chemical composition or arrangement of the surface atoms. ${ }^{4,43,44}$ The product selectivity reflects the presence of acidic, basic, or redox sites. Acidic sites give rise to dimethyl ether, basic sites produce carbon oxides $\left(\mathrm{CO}_{x}\right)$ and redox sites produce formaldehyde, methyl formate, and dimethoxymethane. In Tables 2, 3, and 4 the results are presented of the oxidation of methanol for the catalysts under study.

(i) $\mathrm{SiO}_{2}$. Pure silica shows very poor catalytic performance. The activity of the silica-supported vanadium oxide is signifi- 


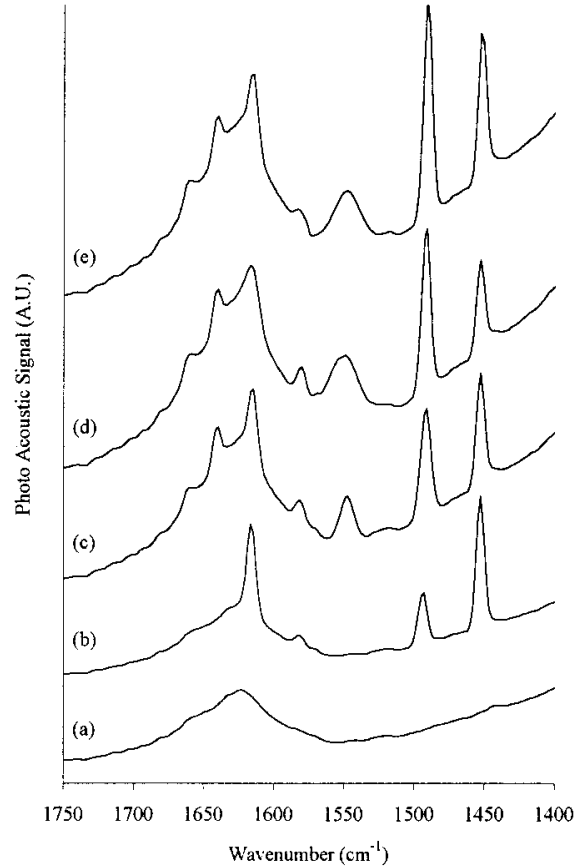

A

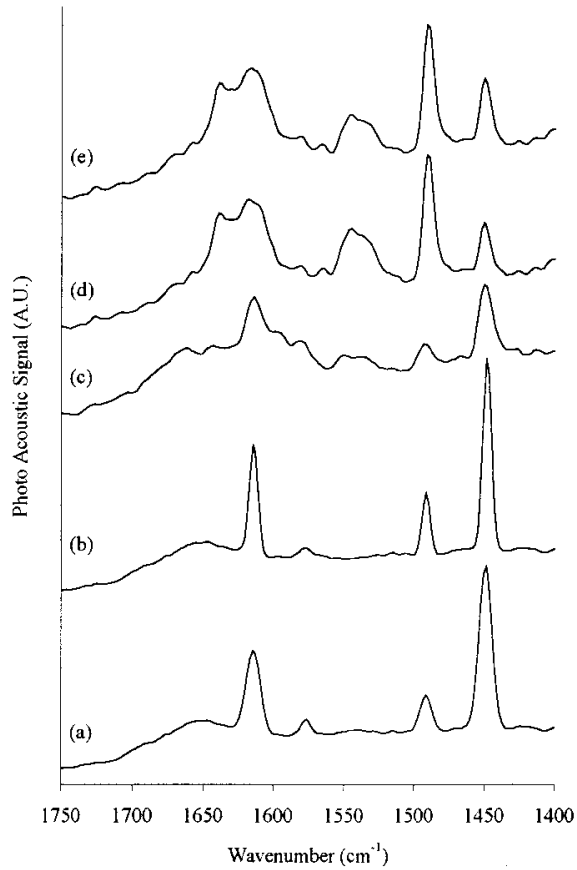

B

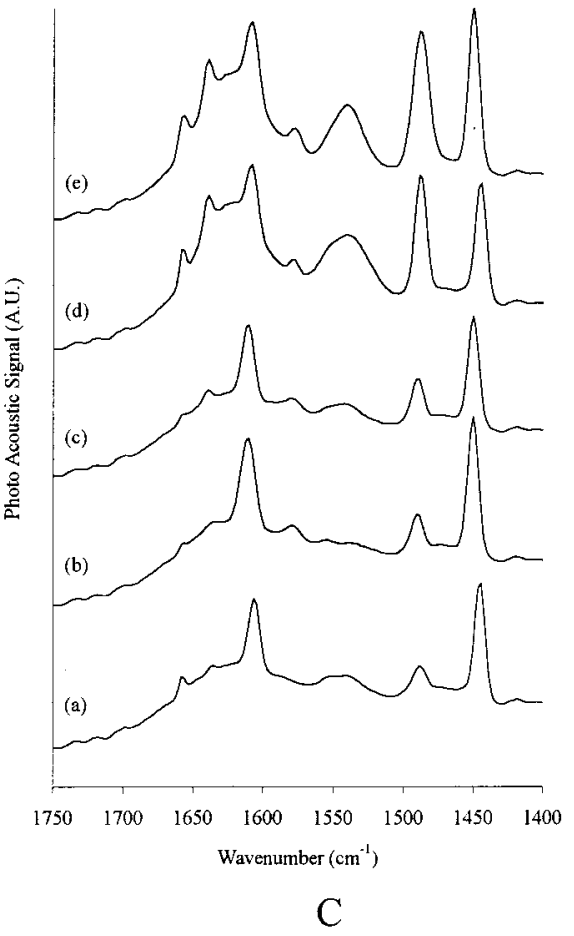

$\mathrm{C}$

Figure 6. FTIR spectra of pyridine adsorbed on (A) silica-supported oxide catalysts; (a) pure $\mathrm{SiO}_{2} ;$ (b) $\mathrm{TaO}_{x} / \mathrm{SiO}_{2}\left(0.21 \mathrm{mmol} / \mathrm{g}\right.$ ); (c) $\mathrm{TaO} / / \mathrm{SiO}{ }_{2}$ $\left(0.47 \mathrm{mmol} / \mathrm{g}\right.$ ); (d) $\mathrm{VO}_{x} / \mathrm{SiO}_{2}\left(0.37 \mathrm{mmol} / \mathrm{g}\right.$ ); (e) $\mathrm{VO}_{x}-\mathrm{TaO}_{x} / \mathrm{SiO}_{2}$ with respective $\mathrm{V}$ and $\mathrm{Ta}$ loading of 0.37 and $0.20 \mathrm{mmol} / \mathrm{g}$, and (B) aluminasupported oxide catalysts; (a) pure $\mathrm{Al}_{2} \mathrm{O}_{3}$; (b) $\mathrm{TaO}_{x} / \mathrm{Al}_{2} \mathrm{O}_{3}\left(0.20 \mathrm{mmol} / \mathrm{g}\right.$ ); (c) $\mathrm{TaO}_{x} / \mathrm{Al}_{2} \mathrm{O}_{3}\left(0.80 \mathrm{mmol} / \mathrm{g}\right.$ ); (d) $\mathrm{VO}_{x} / \mathrm{Al}_{2} \mathrm{O}_{3}\left(0.70 \mathrm{mmol} / \mathrm{g}\right.$ ); (e) $\mathrm{VO}_{x^{-}}$ $\mathrm{TaO}_{x} / \mathrm{Al}_{2} \mathrm{O}_{3}$ with respective $\mathrm{V}$ and $\mathrm{Ta}$ loading of 0.72 and $0.45 \mathrm{mmol} / \mathrm{g}$. C: Zirconia-supported oxide catalysts; (a) pure $\mathrm{ZrO}_{2} ;\left(\right.$ b) $\mathrm{TaO}_{x} / \mathrm{ZrO}_{2}(0.24$ $\mathrm{mmol} / \mathrm{g})$; (c) $\mathrm{TaO}_{x} / \mathrm{ZrO}_{2}(0.60 \mathrm{mmol} / \mathrm{g})$; (d) $\mathrm{VO}_{x} / \mathrm{ZrO}_{2}(0.37 \mathrm{mmol} / \mathrm{g})$; (e) $\mathrm{VO}_{x}-\mathrm{TaO}_{x} / \mathrm{ZrO}_{2}$ with respective $\mathrm{V}$ and $\mathrm{Ta}$ loading of 0.37 and 0.34 $\mathrm{mmol} / \mathrm{g}$.

TABLE 2: Activity and Selectivity of the $\mathrm{SiO}_{2}$ Supported $\mathrm{VO}_{x}, \mathrm{TaO}_{x}$ and $\mathrm{VO}_{x}$ - $\mathrm{TaO}_{x}$ Catalysts

\begin{tabular}{|c|c|c|c|c|c|c|c|c|c|c|}
\hline \multirow[b]{2}{*}{ catalyst } & \multirow{2}{*}{$\begin{array}{c}\mathrm{V} \\
(\mathrm{mmol} / \mathrm{g})\end{array}$} & \multirow{2}{*}{$\begin{array}{c}\mathrm{Ta} \\
(\mathrm{mmol} / \mathrm{g})\end{array}$} & \multirow{2}{*}{$\begin{array}{c}A^{a} \\
\left(10^{-3} \mathrm{~mol} / \mathrm{g} \mathrm{h}\right)\end{array}$} & \multirow{2}{*}{$\begin{array}{c}\mathrm{TOF}^{b} \\
\left(10^{-3} \mathrm{~s}^{-1}\right)\end{array}$} & \multirow{2}{*}{$\begin{array}{l}\mathrm{TOF}_{\text {redox }}{ }^{c} \\
\left(10^{-3} \mathrm{~s}^{-1}\right)\end{array}$} & \multirow{2}{*}{$\begin{array}{l}\mathrm{TOF}_{\text {acid }^{d}} \\
\left(10^{-3} \mathrm{~s}^{-1}\right)\end{array}$} & \multicolumn{4}{|c|}{ selectivity $(\%)^{e}$} \\
\hline & & & & & & & $\overline{\mathrm{CO}_{x}}$ & FA & DME & $\overline{\mathrm{MF}}$ \\
\hline $\mathrm{SiO}_{2}$ & 0.00 & 0.00 & 1.00 & & & & 0.0 & 2.3 & 86.1 & 11.6 \\
\hline $\mathrm{VO}_{x} / \mathrm{SiO}_{2}$ & 0.20 & 0.00 & 4.99 & 6.92 & 6.72 & 0.20 & 0.0 & 25.1 & 2.9 & 72.0 \\
\hline $\mathrm{VO}_{x} / \mathrm{SiO}_{2}$ & 0.36 & 0.00 & 5.23 & 4.04 & 3.83 & 0.21 & 0.0 & 45.2 & 5.1 & 49.7 \\
\hline $\mathrm{VO}_{x} / \mathrm{SiO}_{2}$ & 0.70 & 0.00 & 5.98 & 2.37 & 1.80 & 0.53 & 1.9 & 47.1 & 22.3 & 28.7 \\
\hline $\mathrm{VO}_{x} / \mathrm{SiO}_{2}$ & 1.03 & 0.00 & 5.23 & 1.41 & 0.89 & 0.35 & 12.3 & 45.8 & 24.6 & 17.3 \\
\hline $\mathrm{TaO}_{x} / \mathrm{SiO}_{2}$ & 0.00 & 0.24 & 3.99 & 4.62 & 0.00 & 4.62 & 0.0 & 0.0 & 100.0 & 0.0 \\
\hline $\mathrm{TaO}_{x} / \mathrm{SiO}_{2}$ & 0.00 & 0.47 & 5.28 & 3.12 & 0.94 & 2.19 & 0.0 & 14.0 & 70.0 & 16.0 \\
\hline $\mathrm{VO}_{x}-\mathrm{TaO}_{x} / \mathrm{SiO}_{2}{ }^{f}$ & 0.36 & 0.20 & 5.48 & & & & 0.0 & 74.8 & 25.2 & 0.0 \\
\hline $\mathrm{VO}_{x}-\mathrm{TaO}_{x} / \mathrm{SiO}_{2}^{f}$ & 0.35 & 0.59 & 6.03 & & & & 0.0 & 54.8 & 40.3 & 4.9 \\
\hline $\mathrm{VO}_{x}-\mathrm{TaO}_{x} / \mathrm{SiO}_{2}^{f}$ & 0.24 & 0.60 & 5.08 & & & & 0.0 & 47.5 & 26.6 & 25.9 \\
\hline $\mathrm{TaO}_{x}-\mathrm{VO}_{x} / \mathrm{SiO}_{2}{ }^{g}$ & 0.37 & 0.20 & 5.98 & & & & 0.0 & 74.3 & 25.0 & 0.7 \\
\hline
\end{tabular}

${ }^{a}$ Activity, moles of methanol converted per gram of catalyst and per hour. ${ }^{b}$ Turnover frequency, moles of methanol converted per mole of metal and per second. ${ }^{c}$ Turnover frequency based on the amount of redox products (FA + MF). ${ }^{d}$ Turnover frequency based on the amount of DME. ${ }^{e}$ FA, formaldehyde; DME, dimethyl ether; MF, methyl formate. ${ }^{f}$ Sample prepared by deposition of $\mathrm{TaO}_{x}$ prior to deposition of $\mathrm{VO}_{x} .{ }^{g}$ Sample prepared by deposition of $\mathrm{VO}_{x}$ prior to deposition of $\mathrm{TaO}_{x}$.

cantly higher. $\mathrm{VO}_{x} / \mathrm{SiO}_{2}$ produces mainly oxidation products (formaldehyde and methyl formate). The high selectivity for methyl formate substantiates the high dispersion of the vanadium oxide species on the silica support. ${ }^{45}$ The catalyst surface exhibits an even distribution of vanadia and residual hydroxyl groups of the silica support. Methanol is adsorbed and transformed to formaldehyde on the vanadium sites. However, methanol can react with the residual surface hydroxyl sites as well, which results in adsorbed methoxy groups. ${ }^{46,47}$ Therefore, during the methanol conversion, the formaldehyde formed on the vanadia sites is in close interaction with methoxy groups on the silica sites. Via a hemiacetal intermediate, methyl formate is produced. ${ }^{45}$ With increasing loadings, the formaldehyde selectivity increases, as the surface density of the residual $\mathrm{Si}-$ $\mathrm{OH}$ groups decreases. For the silica samples with $\mathrm{V}$ loadings at which crystalline $\mathrm{V}_{2} \mathrm{O}_{5}$ is observed $(>0.6 \mathrm{mmol} / \mathrm{g})$, the formation of redox products markedly decreases, in favor of the formation of dimethyl ether and carbon oxides.

Silica-supported tantalum oxide catalysts show activities comparable to the $\mathrm{VO}_{x} / \mathrm{SiO}_{2}$. However, the main reaction product is dimethyl ether, indicating the acidic properties of the $\mathrm{TaO}_{x}$ phase. Remarkably, at higher Ta loading the $\mathrm{TaO}_{x} /$ $\mathrm{SiO}_{2}$ samples produce methyl formate and formaldehyde along with the formation of dimethyl ether. This suggests that the interaction of tantala with the silica support gives rise to a considerable redox activity too.

(ii) $\mathrm{Al}_{2} \mathrm{O}_{3}$. Alumina is very active for the dehydration of methanol to dimethyl ether, due to the strong acidity of the alumina surface sites. Deposition of vanadium oxide leads to a decreasing activity and increasing formaldehyde selectivity as a function of the vanadium loading. Moreover, the main product of the reaction is still dimethyl ether, which suggests that the 
TABLE 3: Activity and Selectivity of the $\mathrm{Al}_{2} \mathrm{O}_{3}$ Supported $\mathrm{VO}_{x}, \mathrm{TaO}_{x}$, and $\mathrm{VO}_{x}-\mathrm{TaO}_{x}$ Catalysts

\begin{tabular}{|c|c|c|c|c|c|c|c|c|c|c|}
\hline \multirow[b]{2}{*}{ catalyst } & \multirow{2}{*}{$\begin{array}{c}\mathrm{V} \\
(\mathrm{mmol} / \mathrm{g})\end{array}$} & \multirow{2}{*}{$\begin{array}{c}\mathrm{Ta} \\
(\mathrm{mmol} / \mathrm{g})\end{array}$} & \multirow{2}{*}{$\begin{array}{c}\mathrm{A}^{a} \\
(\mathrm{~mol} / \mathrm{g} \cdot \mathrm{h})\end{array}$} & \multirow{2}{*}{$\begin{array}{l}\mathrm{TOF}^{b} \\
\left(\mathrm{~s}^{-1}\right) \\
\end{array}$} & \multirow{2}{*}{$\begin{array}{c}\mathrm{TOF}_{\text {redox }}{ }^{c} \\
\left(\mathrm{~s}^{-1}\right)\end{array}$} & \multirow{2}{*}{$\begin{array}{c}\mathrm{TOF}_{\text {acid }}{ }^{d} \\
\left(\mathrm{~s}^{-1}\right)\end{array}$} & \multicolumn{4}{|c|}{ selectivity $(\%)^{e}$} \\
\hline & & & & & & & $\mathrm{CO}_{x}$ & FA & DME & MF \\
\hline $\mathrm{Al}_{2} \mathrm{O}_{3}$ & 0.00 & 0.00 & 0.96 & & & & 0.0 & 0.0 & 100.0 & 0.0 \\
\hline $\mathrm{VO}_{x} / \mathrm{Al}_{2} \mathrm{O}_{3}$ & 0.25 & 0.00 & 0.97 & 1.07 & 0.02 & 1.05 & 0.0 & 2.3 & 97.7 & 0.0 \\
\hline $\mathrm{VO}_{x} / \mathrm{Al}_{2} \mathrm{O}_{3}$ & 0.70 & 0.00 & 0.85 & 0.34 & 0.05 & 0.29 & 0.0 & 14.0 & 86.0 & 0.0 \\
\hline $\mathrm{VO}_{x} / \mathrm{Al}_{2} \mathrm{O}_{3}$ & 1.20 & 0.00 & 0.70 & 0.16 & 0.04 & 0.12 & 0.0 & 21.7 & 77.3 & 1.0 \\
\hline $\mathrm{VO}_{x} / \mathrm{Al}_{2} \mathrm{O}_{3}$ & 2.10 & 0.00 & 0.50 & 0.07 & 0.02 & 0.04 & 2.0 & 29.1 & 67.9 & 1.0 \\
\hline $\mathrm{TaO}_{x} / \mathrm{Al}_{2} \mathrm{O}_{3}$ & 0.00 & 0.20 & 0.78 & 1.08 & 0.00 & 1.08 & 0.0 & 0.0 & 100.0 & 0.0 \\
\hline $\mathrm{TaO}_{x} / \mathrm{Al}_{2} \mathrm{O}_{3}$ & 0.00 & 0.80 & 0.53 & 0.18 & 0.00 & 0.18 & 0.0 & 0.0 & 100.0 & 0.0 \\
\hline $\mathrm{VO}_{x}-\mathrm{TaO}_{x} / \mathrm{Al}_{2} \mathrm{O}_{3}^{f}$ & 0.72 & 0.45 & 0.50 & & & & 0.0 & 13.1 & 86.9 & 0.0 \\
\hline $\mathrm{TaO}_{x}-\mathrm{VO}_{x} / \mathrm{Al}_{2} \mathrm{O}_{3}{ }^{g}$ & 0.69 & 0.41 & 0.50 & & & & 0.0 & 12.8 & 87.2 & 0.0 \\
\hline
\end{tabular}

${ }^{a}$ Activity, moles of methanol converted per gram catalyst and per hour. ${ }^{b}$ Turnover frequency, moles of methanol converted per mole of metal and per second. ${ }^{c}$ Turnover frequency based on the amount of redox products (FA + MF). ${ }^{d}$ Turnover frequency based on the amount of DME. ${ }^{e}$ FA, formaldehyde; DME, dimethyl ether; MF, methyl formate. ${ }^{f}$ Sample prepared by deposition of $\mathrm{TaO}_{x}$ prior to deposition of $\mathrm{VO}_{x} .{ }^{g}$ Sample prepared by deposition of $\mathrm{VO}_{x}$ prior to deposition of $\mathrm{TaO}_{x}$.

TABLE 4: Activity and Selectivity of the $\mathrm{ZrO}_{2}$ Supported $\mathrm{VO}_{x}, \mathrm{TaO}_{x}$, and $\mathrm{VO}_{x}$-TaO $\mathrm{Tatalysts}_{x}$

\begin{tabular}{|c|c|c|c|c|c|c|c|c|c|c|}
\hline \multirow[b]{2}{*}{ catalyst } & \multirow{2}{*}{$\begin{array}{c}\mathrm{V} \\
(\mathrm{mmol} / \mathrm{g})\end{array}$} & \multirow{2}{*}{$\begin{array}{c}\mathrm{Ta} \\
(\mathrm{mmol} / \mathrm{g})\end{array}$} & \multirow{2}{*}{$\begin{array}{c}\mathrm{A}^{a} \\
(\mathrm{~mol} / \mathrm{g} \cdot \mathrm{h})\end{array}$} & \multirow{2}{*}{$\begin{array}{l}\mathrm{TOF}^{b} \\
\left(\mathrm{~s}^{-1}\right)\end{array}$} & \multirow{2}{*}{$\begin{array}{c}\mathrm{TOF}_{\text {redox }}{ }^{c} \\
\left(\mathrm{~s}^{-1}\right)\end{array}$} & \multirow{2}{*}{$\begin{array}{c}\mathrm{TOF}_{\text {acid }^{d}}{ }^{\left(\mathrm{s}^{-1}\right)}\end{array}$} & \multicolumn{4}{|c|}{ selectivity $(\%)^{e}$} \\
\hline & & & & & & & $\mathrm{CO}_{x}$ & FA & DME & MF \\
\hline $\mathrm{ZrO}_{2}$ & 0.00 & 0.00 & 0.05 & & & & 0.0 & 0.0 & 15.2 & 84.8 \\
\hline $\mathrm{VO}_{x} / \mathrm{ZrO}_{2}$ & 0.09 & 0.00 & 0.55 & 1.69 & 1.53 & 0.16 & 0.0 & 68.3 & 9.7 & 22.0 \\
\hline $\mathrm{VO}_{x} / \mathrm{ZrO}_{2}$ & 0.19 & 0.00 & 0.65 & 0.95 & 0.91 & 0.04 & 0.0 & 87.1 & 3.8 & 9.1 \\
\hline $\mathrm{VO}_{x} / \mathrm{ZrO}_{2}$ & 0.36 & 0.00 & 1.00 & 0.77 & 0.76 & 0.01 & 0.0 & 92.0 & 1.7 & 6.3 \\
\hline $\mathrm{VO}_{x} / \mathrm{ZrO}_{2}$ & 1.02 & 0.00 & 0.55 & 0.15 & 0.12 & 0.01 & 10.3 & 74.9 & 8.1 & 6.7 \\
\hline $\mathrm{TaO}_{x} / \mathrm{ZrO}_{2}$ & 0.00 & 0.15 & 0.03 & 0.06 & 0.05 & 0.02 & 0.0 & 0.0 & 28.4 & 71.6 \\
\hline $\mathrm{TaO}_{x} / \mathrm{ZrO}_{2}$ & 0.00 & 0.24 & 0.03 & 0.04 & 0.01 & 0.03 & 0.0 & 0.0 & 83.8 & 16.2 \\
\hline $\mathrm{VO}_{x}-\mathrm{TaO}_{x} / \mathrm{ZrO}_{2}^{f}$ & 0.36 & 0.05 & 0.98 & & & & 0.0 & 92.0 & 4.0 & 4.0 \\
\hline $\mathrm{VO}_{x}-\mathrm{TaO}_{x} / \mathrm{ZrO}_{2}^{f}$ & 0.36 & 0.17 & 0.98 & & & & 0.0 & 92.2 & 4.9 & 2.9 \\
\hline $\mathrm{VO}_{x}-\mathrm{TaO}_{x} / \mathrm{ZrO}_{2}^{f}$ & 0.36 & 0.34 & 0.97 & & & & 0.0 & 91.0 & 6.0 & 3.0 \\
\hline $\mathrm{VO}_{x}-\mathrm{TaO}_{x} / \mathrm{ZrO}_{2}^{f}$ & 0.36 & 0.58 & 0.64 & & & & 0.0 & 88.7 & 7.7 & 3.6 \\
\hline $\mathrm{TaO}_{x}-\mathrm{VO}_{x} / \mathrm{ZrO}_{2}^{g}$ & 0.35 & 0.20 & 0.98 & & & & 0.0 & 92.5 & 5.8 & 1.7 \\
\hline
\end{tabular}

${ }^{a}$ Activity, moles of methanol converted per gram of catalyst and per hour. ${ }^{b}$ Turnover frequency, moles of methanol converted per mole of metal and per second. ${ }^{c}$ Turnover frequency based on the amount of redox products (FA + MF). ${ }^{d}$ Turnover frequency based on the amount of DME. ${ }^{e}$ FA, formaldehyde; DME, dimethyl ether; MF, methyl formate. ${ }^{f}$ Sample prepared by deposition of $\mathrm{TaO}_{x}$ prior to deposition of $\mathrm{VO}_{x} .{ }^{g}$ Sample prepared by deposition of $\mathrm{VO}_{x}$ prior to deposition of $\mathrm{TaO}_{x}$.

alumina acid sites are much more active than the redox activity of the vanadia sites.

Alumina-supported tantala shows exclusive dehydration activity. Increasing the Ta loading on alumina also results in decreasing activity, which indicates that the surface $\mathrm{TaO}_{x}$ sites (although acidic) are less active than the active sites of the alumina surface. Therefore, the overall activity of the $\mathrm{TaO}_{x} l$ $\mathrm{Al}_{2} \mathrm{O}_{3}$ samples is attributed to the reactivity of the support sites rather than on the reactivity of the tantala sites.

(iii) $\mathrm{ZrO}_{2}$. Pure zirconia exhibits some redox activity and produces methyl formate, besides some dimethyl ether rising from the acidic surface sites. Deposition of vanadium oxide significantly increases the activity and leads to a quite selective formation of formaldehyde (except for samples containing crystalline fractions of $\mathrm{V}_{2} \mathrm{O}_{5}$ ).

Deposition of $\mathrm{TaO}_{x}$ on zirconia leads to a slightly increased activity in comparison to the pure support. The acidic properties of the tantala sites result in a marked increase of the dimethyl ether selectivity.

It is well established that supported vanadium oxide catalysts show quite different activity and selectivity when the support is changed. A readily reducible oxide support surface gives rise to a more active supported vanadium oxide phase.,48 This means that the reactivity depends on the reduction characteristics of the $\mathrm{V}-\mathrm{O}$-support bonds rather than the characteristics of the terminal $\mathrm{V}=\mathrm{O}$ bonds. As a result, the redox activity of the supported vanadium oxides increases in the order $\mathrm{SiO}_{2}<\mathrm{Al}_{2} \mathrm{O}_{3}$ $<\mathrm{ZrO}_{2} \cong \mathrm{TiO}_{2}$ according to the better surface reducibility of the support. This can also be inferred from the $\mathrm{TOF}_{\text {redox }}$ values of the $\mathrm{VO}_{x} / \mathrm{SiO}_{2}, \mathrm{VO}_{x} / \mathrm{Al}_{2} \mathrm{O}_{3}$ and $\mathrm{VO}_{x} / \mathrm{ZrO}_{2}$ catalysts in Tables
TABLE 5: Summary of the Spectral Features of the Supported Vanadia and Supported Tantala Catalysts

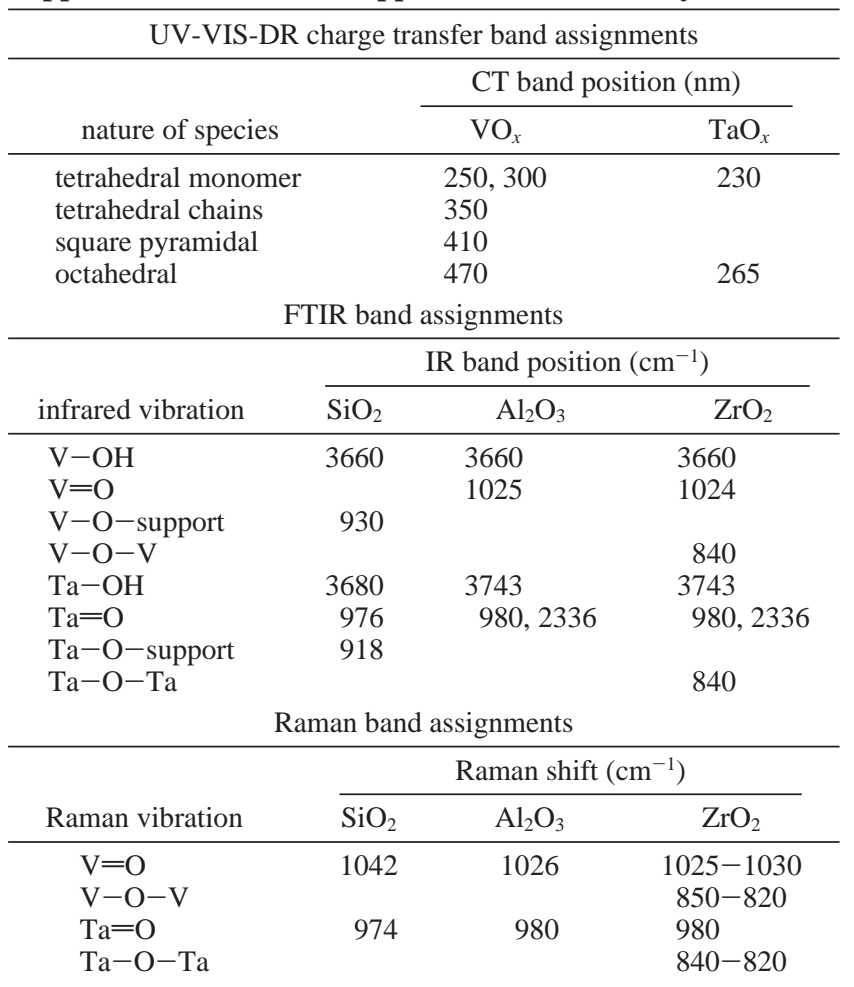

2, 3, and 4. However, the correlation between activity of the surface tantala species and the surface reducibility of the support 
is not like in the case of vanadia. The total activity increases in the order $\mathrm{SiO}_{2}<\mathrm{Al}_{2} \mathrm{O}_{3}<\mathrm{ZrO}_{2}$, similar to the vanadia case. However, the main product of the reaction is dimethyl ether (except for some methyl formate on the $\mathrm{ZrO}_{2}$ supported samples, which is due to the contribution of exposed zirconia redox sites), which shows that the tantalum oxide exhibits predominantly acidic characteristics. In addition, the total activity of the silicasupported tantala is almost the same as silica-supported vanadia, while the total activity of the zirconia-supported tantala is much lower than the vanadia analogue. Clearly, the reducibility of the support surface has a much stronger effect on the surface vanadia species than on the surface tantala sites.

(iv) $\mathrm{VO}_{x}-\mathrm{TaO}_{x}$. The difference in reactivity between vanadia and tantala is also reflected in the supported mixed oxide catalysts. The addition of tantala to silica-supported vanadia increases the total activity and the selectivities toward formaldehyde and dimethyl ether. On the other hand, the addition of tantala to alumina- and zirconia-supported vanadia does not affect the catalytic performance, which substantiates that on readily reducible supports the vanadia sites are much more active than the tantala sites. In addition, reversing the sequence of deposition of $\mathrm{VO}_{x}$ and $\mathrm{TaO}_{x}$ does not lead to significant changes in activity and selectivity. The only exception is the zirconiasupported catalyst prepared by the deposition of vanadium oxide on the amorphous tantalum overlayers (samples with high $\mathrm{Ta}$ loadings). The activity of this sample is significantly lower, although the selectivity pattern is the same as for the other zirconia-supported mixed vanadia-tantala. In this case a part of the vanadia sites is linked to the tantalum oxide overlayer. Apparently, the poor reducibility of the tantala phase leads to a decreased activity of these vanadia sites.

\section{Discussion}

Molecular Structures and Surface Properties of Tantalum Oxide Containing Catalysts. The supported tantalum oxide catalysts investigated clearly show the existence of two types of surface configurations, depending on the properties of the oxide support and the surface coverage. The spectral features of the supported oxide catalysts obtained in this study are summarized in Table 5.

$\mathrm{TaO}_{x} / \mathrm{SiO}_{2}$. The spectroscopic study of the silica-supported tantala catalyst shows at low Ta loading a highly uniform surface structure, characterized by a charge-transfer band in the UVvis-DRS spectra at $233 \mathrm{~nm}$, and $\mathrm{Ta}=\mathrm{O}$ bands at 974 and 976 $\mathrm{cm}^{-1}$ in Raman and infrared, respectively. The $\mathrm{Ta}=\mathrm{O}$ species are linked to the silica support by $\mathrm{Si}-\mathrm{O}-\mathrm{Ta}$ bridges, which is inferred from the consumption of $\mathrm{Si}-\mathrm{OH}$ groups after deposition of the tantala phase, and the appearance of a broad IR band at $918 \mathrm{~cm}^{-1}$. A recent EXAFS study of silica-supported tantalum oxide $^{49}$ revealed that the surface oxide species are present as isolated tantalate species with one short $\mathrm{Ta}-\mathrm{O}$ bond and three long $\mathrm{Ta}-\mathrm{O}$ bonds. This means that at low loadings the deposited $\mathrm{TaO}_{x}$ species are in an isolated tetrahedral configuration. However, the spectroscopic results from this study suggest that at higher loadings an additional surface configuration occurs, which gives rise to a CT band around $260 \mathrm{~nm}$ and exhibits $\mathrm{Ta}-$ $\mathrm{OH}$ species (IR band at $3680 \mathrm{~cm}^{-1}$ ). On the other hand, the octahedrally coordinated $\mathrm{Ta}$ in pure $\mathrm{Ta}_{2} \mathrm{O}_{5}$ shows similar spectroscopic features. Therefore, the second surface structure is attributed to octahedrally coordinated tantala, which is probably polymerized via $\mathrm{Ta}-\mathrm{O}-\mathrm{Ta}$ bridges.

Furthermore, it seems that higher Ta loadings can be achieved by the ALD gas phase technique in comparison to the liquid phase synthesis, before octahedral (and probably polymerized) tantala species occur. The difference between gas and liquid phase can be explained by the structure of the tantalum ethoxide precursor. Most simple tantalum alkoxides adopt binuclear structures $\left(\mathrm{Ta}_{2}(\mathrm{OR})_{8}(\mu-\mathrm{OR})_{2}\right)$, with two bridging alkoxide ligands. Evaporation of the alkoxide occurs only after dissociation to monomers $\left(\mathrm{Ta}(\mathrm{OR})_{5}\right) .{ }^{16}$ This means that during the ALD process monomeric species are interacting with the support surface, resulting in a much better distribution of isolated tantalum centers over the support surface. Still, liquid-phase samples with loadings up to $0.8 \mathrm{mmol} / \mathrm{g}(15 \mathrm{wt} \% \mathrm{Ta})$ show no evidence for the formation of crystalline $\mathrm{Ta}_{2} \mathrm{O}_{5}$.

The pyridine adsorption experiments showed that the silicasupported tantala phase is mainly Lewis acidic, although at high loadings also Brønsted acidity occurs, due to the presence of the $\mathrm{Ta}-\mathrm{OH}$ groups. In the oxidation of methanol the supported tantala catalysts show excellent dehydration performance due to the acidic properties, but at higher loadings the interaction between tantala and silica causes some redox activity as well. This may be due to the ease of hydrolysis of the bridging $\mathrm{Ta}-$ $\mathrm{O}-\mathrm{Si}$ bonds during the methanol oxidation, as reported for the silica-supported niobia case. ${ }^{46,50}$ However, a detailed understanding for this redox behavior is not yet established and a thorough oxidation study is required in order to clarify this issue.

$\mathrm{TaO}_{x} / \mathrm{Al}_{2} \mathrm{O}_{3}$. The alumina-supported tantalum oxides also exhibit CT band around $235 \mathrm{~nm}$ which indicates that the tantalum species are present in an isolated tetrahedral configuration. However, absorption at $265 \mathrm{~nm}$ suggests that even at low coverages a minor part of the $\mathrm{TaO}_{x}$ is octahedrally coordinated, even in the case of the ALD-prepared samples. $\mathrm{Ta}=\mathrm{O}$ species are observed by an IR absorption at $980 \mathrm{~cm}^{-1}$. At higher coverages an amorphous tantalum oxide overlayer exists, giving rise to an IR band at $2336 \mathrm{~cm}^{-1}$ and $\mathrm{Ta}-\mathrm{OH}$ species at $3743 \mathrm{~cm}^{-1}$ (the band at $3680 \mathrm{~cm}^{-1}$ which is also associated with $\mathrm{Ta}-\mathrm{OH}$ cannot be distinguished unambiguously due to the IR bands of the support hydroxyls).

The Ta sites supported on alumina show Lewis acidity and an exclusive dehydration activity in the oxidation of methanol. However, the alumina sites exhibit much higher activity than the tantala sites.

$\mathrm{TaO}_{x} / \mathrm{ZrO}_{2}$. On zirconia, the majority of the tantala species is in a polymeric octahedral coordination, even at low loadings, which is substantiated by the CT band at $270 \mathrm{~nm}$ and the Ta$\mathrm{O}-\mathrm{Ta}$ vibrations around $820-830 \mathrm{~cm}^{-1}$ in infrared and Raman. Similar to the alumina samples, the zirconia-supported tantala shows IR absorption at 2335 and $3743 \mathrm{~cm}^{-1}$ at higher coverages, indicating the presence of an amorphous $\mathrm{Ta}_{2} \mathrm{O}_{5}$ layer.

Zirconia-supported tantalum oxide is also Lewis acidic, which results in an almost exclusive dehydration activity in the oxidation of methanol.

It is concluded that at low Ta coverage the tantala species have exclusively $T_{d}$ symmetry on silica, whereas both $T_{d}$ and $O_{h}$ symmetry of Ta is observed on alumina, and mainly $O_{h}$ symmetry of Ta is observed on zirconia. This can be explained by the fact that metal ions in an overlayer at low coverage assume the symmetry of the support metal ions. It is known that silica shows only $T_{d}$ symmetry, ${ }^{51}$ whereas alumina shows a surface constructed of both $T_{d}$ and $O_{h}$ symmetries, ${ }^{52,53}$ and zirconia shows only $O_{h}$ symmetry ${ }^{54}$ if one considers both nearest and next-nearest oxygen atoms.

Supported $\mathrm{VO}_{x}-\mathrm{TaO}_{x}$ Mixed Oxides. The spectroscopic and catalytic comparison between supported vanadia and tantala oxide was very useful to deduce valuable information on the tantalum oxide structure and properties. The spectroscopic study of the supported mixed oxides leads to similar conclusions as in the case of the supported tantala and supported vanadia as 
such. Interestingly, the structure and dispersion of one metal oxide species is nearly unaffected by the presence of the other metal oxide species nor by the grafting sequence of the oxides.

The catalytic properties are significantly determined by the oxide support. Silica-supported vanadia-tantala catalysts exhibit high selectivity toward formaldehyde and dimethyl ether, according to the presence of both active redox and active acid centers. In contrast, on a readily reducible support like $\mathrm{ZrO}_{2}$, the vanadia species are much more active than the tantala sites. In fact, the oxidation of methanol requires only one active surface site; therefore, the catalytic performance of the zirconiasupported catalysts is not promoted by the tantala species. Consequently, a mixed vanadia-tantala catalyst is useful for reactions that require both active redox and efficient acidic surface sites.

\section{Conclusions}

(1) Supported tantalum oxide show basically two types of molecular structures. On silica at low coverages, isolated tetrahedral species occur, with a short $\mathrm{Ta}=\mathrm{O}$ bond and three bridging $\mathrm{Ta}-\mathrm{O}$-support bonds. At higher coverages, octahedrally coordinated tantala species occur. The alumina-supported tantala shows both surface species already at low coverages, whereas the zirconia samples predominantly exhibit polymerized, octahedrally configured tantalum oxide. In addition, the formation of an amorphous surface overlayer is revealed on both alumina and zirconia at high tantala coverages.

(2) The atomic layer deposition of the tantalum ethoxide precursor results in a better uniformity of the surface tantala species in comparison to the liquid phase. This is due to the binuclear structure of the tantalum alkoxide in the liquid phase, and the dissociation to a monomeric structure after evaporation.

(3) The supported tantala catalysts possess unique surface properties. The infrared study of the adsorption of pyridine showed the Lewis acidic characteristics of the surface tantala species. This is also reflected in the oxidation of methanol, which reveals that the supported tantala shows unique acidic properties. Suprisingly, the interaction of tantala with the silica support induces redox properties too.

(4) Supported vanadia-tantala mixed oxides are very well dispersed on the support surfaces. The grafting sequence does not lead to significant changes in surface structure or methanol oxidation performance. The ternary vanadia-tantala-support catalyst system is potentially useful in reactions requiring both redox and acid sites.

Acknowledgment. This work was supported by the FWO Vlaanderen (Research project G.0446.99). M. Baltes thanks the European Science Foundation (ESF) for a short-term fellowship in the scope of the ESF network on "Elementary Steps of Layer Growth in the Fabrication of Novel Materials by Atomic Layer Epitaxy", for a research stay at Fortum Oil and Gas Oy, Espoo, Finland. P. Van Der Voort is a postdoctoral fellow of the F.W.O. Vlaanderen. The authors are grateful to Mrs. Minna Helsto and Mrs. Mirja Rissanen for their aid in the experimental work.

\section{References and Notes}

(1) Koranne, M.; Goodwin, J. G.; Marcelin, G. J. Catal. 1994, 148 , 388.

(2) Dias, C. R.; Portela, M. F.; Bond, G. C. J. Catal. 1995, 157, 344.

(3) Bond, G. C.; Tahir, S. F. Appl. Catal. 1991, 71, 1.

(4) Deo, G.; Wachs, I. E.; Haber J. Crit. Rev. Surf. Chem. 1994, 4, 141.

(5) Dunn, J. P.; Stenger, H. P.; Wachs, I. E. Catal. Today 1999, 51, 301.

(6) Vogt, E. T. V.; Boot, A.; van Dillen, A. J.; Geus, J. W.; Janssen, F. J. J. G.; van den Kerkhof, F. M. G. J. Catal. 1988, 114, 313.
(7) Wachs, I. E.; Deo, G.; Weckhuysen, B. M.; Andreini, A.; Vuurman, M. A.; de Boer, M.; Amiridis, M. D. J. Catal. 1996, 161, 211

(8) Tran, K.; Hanning-Lee, M. A.; Biswas, A.; Stiegman, A. E.; Scott, G. W. J. Am. Chem. Soc. 1995, 117, 2618.

(9) Wachs, I. E.; Briand, L. E.; Jehng, J. M.; Burcham, L.; Gao, X. Catal. Today 2000, 57, 323.

(10) Datka, J.; Turek, A. M.; Jehng, J. M.; Wachs, I. E. J. Catal. 1992, $135,186$.

(11) Deo, G.; Wachs, I. E. J. Catal. 1994, 146, 335.

(12) Viparelli, P.; Ciambelli, P.; Lisi, L.; Ruoppolo, G.; Russo, G.; Volta, J. C. Appl. Catal., A 1999, 184, 291.

(13) Jehng, J. M.; Wachs, I. E. J. Phys. Chem. 1991, 95, 7373.

(14) Kukli, K.; Ritala, M.; Matero, R.; Leskelä, M. J. Cryst. Growth 2000, 212,459 .

(15) Meng, J. F.; Rai, B. K.; Katiyar, R. S.; Bhalla, A. S. J. Phys. Chem. Solids 1997, 58, 1503.

(16) Pollard, K. D.; Puddephatt, R. J. Chem. Mater. 1999, 11, 1069.

(17) Ushikubo, T. Catal. Today 2000, 57, 331.

(18) Ushikubo, T.; Wada, K. J. Catal. 1994, 148, 138.

(19) Ushikubo, T.; Wada, K. Appl. Catal., A 1995, 124, 19.

(20) Guiu, G.; Grange, P. J. Catal. 1995, 156, 132.

(21) Van Der Voort, P.; Babitch, I. B.; Grobet, P. J.; Verberckmoes, A A.; Vansant, E. F. J. Chem. Soc., Faraday Trans. 1996, 92, 3635.

(22) Baltes, M.; Van Der Voort, P.; Collart, O.; Vansant, E. F. J. Porous Mater. 1998, 5, 357.

(23) Baltes, M.; Collart, O.; Van Der Voort, P.; Vansant, E. F. Langmuir 1999, 15,5841 .

(24) Baltes, M.; Van Der Voort, P.; Weckhuysen, B. M.; Rao, R. R.; Catana, G.; Schoonheydt, R. A.; Vansant, E. F. Phys. Chem. Chem. Phys. 2000, 2, 2673.

(25) Baltes, M.; Cassiers, K.; Van Der Voort, P.; Weckhuysen, B. M.; Schoonheydt, R. A.; Vansant, E. F. J. Catal. 2001, 197, 160.

(26) Huuhtanen, J.; Sanati, M.; Andersson, A.; Andersson, S. L. T. Appl. Catal A 1993, 97, 197.

(27) Prinetto, F.; Ghiotto, G.; Occhiuzzi, M.; Indovina, V. J. Phys. Chem. B 1998, 102, 10316.

(28) Haukka, S.; Kytökivi, A.; Lakomaa, E.-L.; Lehtovirta, U.; Lindblad, M.; Lujala, V.; Suntola, T. In Preparation of Catalysts VI, Scientific Bases for the Preparation of Heterogeneous Catalysts; Poncelet, G., Ed.; p 957, Elsevier Science, Amsterdam, 1995; p 957.

(29) Kytökivi, A.; Lakomaa, E.-L.; Root, A.; Österholm, H.; Jacobs, J.-P.; Brongersma, H. H. Langmuir 1997, 13, 2717.

(30) Kytökivi, A.; Jacobs, J.-P.; Hakuli, A.; Meriläinen, J.; Brongersma, H. H. J. Catal. 1996, 162, 190.

(31) Schraml-Marth, M.; Wokaun, A.; Pohl, M.; Krauss, H. L. J. Chem. Soc., Faraday Trans 1991, 87, 2635.

(32) Scharf, U.; Schraml-Marth, M.; Wokaun, A.; Baiker, A. J. Chem. Soc., Faraday Trans. 1991, 87, 3299.

(33) Zhang, J.-Y.; Lim, B.; Boyd, I. W. Thin Solid Films 1998, 336, 340 .

(34) Vuurman, M. A.; Stufkens, D. J.; Oskam, A.; Deo, G.; Wachs, I. E. J. Chem. Soc., Faraday Trans. 1996, 92, 3259.

(35) Ono, H.; Koyanagi, K. Appl. Phys. Lett. 2000, 77, 1431.

(36) Kantcheva, M. Phys. Chem. Chem. Phys. 2000, 2, 3043.

(37) Szanics, J.; Okubo, T.; Kakihana, M. J. Alloy Compd. 1998, 281, 206.

(38) Su, S. C.; Bell, A. T. J. Phys. Chem. 1998, 102, 7000.

(39) Sanati, M.; Andersson, A.; Wallenberg, L. R.; Rebenstorf, B. Appl. Catal., A 1993, 106, 51.

(40) Kataoka, T.; Dumesic, J. A. J. Catal. 1988, 112, 66.

(41) Rajagopal, S.; Marzari, J. A.; Miranda, R. J. Catal. 1995, 151, 192.

(42) Damyanova, S.; Grange, P.; Delmon, B. J. Catal. 1997, 168, 421.

(43) Tatibouët, J. M. Appl. Catal., A 1997, 148, 213.

(44) Forzatti, P.; Tronconi, E.; Elmi, A. S.; Busca, G. Appl. Catal., A 1997, 157, 387.

(45) Louis, C.; Tatibouët, J. M.; Che, M. J. Catal. 1988, 109, 354.

(46) Jehng, J.-M.; Hu, H.; Gao, X.; Wachs, I. E. Catal. Today 1996, 28,335 .

(47) Gao, X.; Bare, S. R.; Weckhuysen, B. M.; Wachs, I. E. J. Phys. Chem. B 1998, 102, 10842.

(48) Deo, G.; Wachs, I. E. J. Catal. 1994, 146, 323.

(49) Tanaka, T.; Nojima, H.; Yamamoto, T.; Takenaka, S.; Funabiki, T.; Yoshida, S. Phys. Chem. Chem. Phys. 1999, 1, 5235.

(50) Wachs, I. E.; Jehng, J.-M.; Deo, G.; Hu, H.; Arora, N. Catal. Today 1996, 28, 199.

(51) Vansant, E. F.; Van Der Voort, P.; Vrancken, K. C. Characterization and Chemical Modification of the Silica Surface, Studies in Surface Science and Catalysis; Elsevier: Amsterdam, 1995; Vol. 93.

(52) Peri, J. B. J. Phys. Chem. 1966, 70, 3168.

(53) Knözinger, H.; Ratnasamy, P. Catal. Rev. Sci. Eng. 1978, 17, 31.

(54) Clearfield, A.; Serette, G. P. D.; Khazi-Syed, A. H. Catal. Today 1994, 20, 295. 